\title{
Transactional distance and student motivation: Student perception of teacher immediacy, solidarity toward peer students and student motivation in distance education
}

Hye Yoon Jung

West Virginia University

Follow this and additional works at: https://researchrepository.wvu.edu/etd

\author{
Recommended Citation \\ Jung, Hye Yoon, "Transactional distance and student motivation: Student perception of teacher \\ immediacy, solidarity toward peer students and student motivation in distance education" (2006). \\ Graduate Theses, Dissertations, and Problem Reports. 4237. \\ https://researchrepository.wvu.edu/etd/4237
}

This Dissertation is protected by copyright and/or related rights. It has been brought to you by the The Research Repository @ WVU with permission from the rights-holder(s). You are free to use this Dissertation in any way that is permitted by the copyright and related rights legislation that applies to your use. For other uses you must obtain permission from the rights-holder(s) directly, unless additional rights are indicated by a Creative Commons license in the record and/ or on the work itself. This Dissertation has been accepted for inclusion in WVU Graduate Theses, Dissertations, and Problem Reports collection by an authorized administrator of The Research Repository @ WVU.

For more information, please contact researchrepository@mail.wvu.edu. 
Transactional Distance and Student Motivation:

Student Perception of Teacher Immediacy, Solidarity toward Peer Students and Student Motivation in Distance Education

\author{
Hye Yoon Jung \\ A DISSERTATION \\ Submitted to \\ The College of Human Resources and Education \\ at \\ West Virginia University \\ in Partial Fulfillment of the Requirements \\ for the Degree of \\ Doctor of Education \\ In \\ Technology Education \\ Department of Advanced Education \\ Neal Shambaugh \\ David L. McCrory \\ Jaci Webb-Dempsey \\ James C. McCroskey \\ Sebastian Diaz \\ Department of Advanced Educational Studies \\ College of Human Resources and Education \\ Morgantown, West Virginia \\ 2006
}

Keywords: Transactional Distance, Transactional Distance Theory, Distance Education, Motivation, Immediacy, Solidarity, Videoconferencing, MBA, Adult Learner

Copyright 2006 


\begin{abstract}
Transactional Distance and Student Motivation:

Student Perception of Teacher Immediacy, Solidarity toward Peer Students and

Student Motivation in Distance Education
\end{abstract}

Hye Yoon Jung

Transactional Distance Theory is conceptually significant in that the core nature of distance in distance education is not a geographical or temporal distance but a psychological or communicational distance between students and their teacher(s), as well as among students. In spite of the conceptual significance of the transactional distance theory, the interrelationships among the construct variables and propositions of the theory are unclear. The majority of studies on transactional distance theory either used the theory solely as a conceptual framework, or proposed the refinement of the theory. Literature review indicated that the theory was found to be invalid and unreliable. No measurements have been consistently used to measure transactional distance.

This study focused on the conceptual significance of transactional theory through the use of concepts and measurements from Communication Studies. This study made an effort to investigate Moore's theory of transactional distance with the concepts of 'immediacy' and 'solidarity,' which are often used in the field of Communication Studies. The operational definition of transactional distance between teacher and students (TDST) is students' perception of teachers' immediacy behavior and that of transactional distance among students (TDSS) is students' perception of the learner.

By providing a measurable communication variable as operational definition of transactional distance, this study showed the potential of transactional distance as a measurable variable in a theory. This study sampled seventy-nine Executive Master's of Business Administration (EMBA) students in videoconferencing classrooms. The findings indicated that offsite students who do not have their instructor in their classroom developed higher solidarity toward their classmates in the same site than onsite students whose instructors were present in their classroom. No significant association was found between student motivation and student perception of psychological distance toward their instructor or toward their classmates. 


\section{ACKNOWLEDGEMENTS}

I would like to thank several people for providing me with guidance and encouragement to complete this dissertation. I truly want to express my appreciation to Dr. Neal Shambaugh for persevering with me as my advisor throughout the time it took to complete this research and write the dissertation. He continually stimulated my analytical thinking and greatly assisted me with academic writing.

I am also very grateful for having an exceptional doctoral committee and wish to thank Drs. Diaz, Webb-Dempsey, McCrory and McCroskey for their continual support and encouragement. I owe a special note of gratitude to Dr. McCroskey, whose knowledge, research experience and insights inspired me to grow as a scholar. I need to thank Dr. Webb-Dempsey who has given me emotional support and has shown genuine interest in my academic activities from the beginning of my doctoral program to the completion of my dissertation. I also want to thank Dr. McCrory for his insight and for being available when I sought help and support. My thanks also go to Dr. Diaz for his help with my research methods section. At many moments of frustration during the course of the dissertation study, my advisor and committee members were always on my side to encourage me to keep moving forward. I also would like to thank Executive MBA program faculty members, staff and students for giving me so much assistance and allowing me to conduct my dissertation research in their program.

I must acknowledge friends, colleagues, students, teachers, and librarians who assisted, advised, and supported my research and writing efforts over the years. Especially, I need to express my gratitude to Frank, Barbara, Melody, Jocelyn, John, Krista, Laura, Lee Ann, Lori, Justin and Yetta, whose friendship, hospitality, knowledge, and wisdom have supported, enlightened, and entertained me over the many years of our friendship. They have consistently helped me keep perspective on what is important in life and shown me how to deal with reality. Lastly, but not least, I would like to thank my family members for their understanding and love during the past few years-- especially, my parents' dedication and many years of support which, in the end, made this dissertation possible. I sincerely thank those who I acknowledge here and countless others I may have forgotten. 
TABLE OF CONTENTS

\section{PAGE}

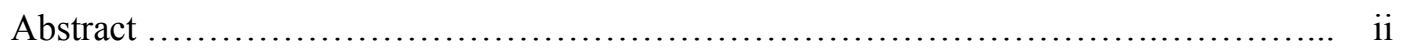

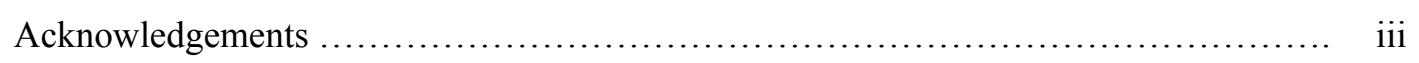

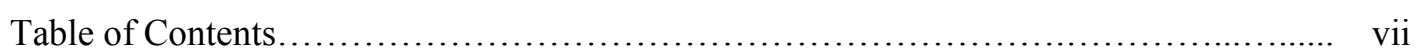

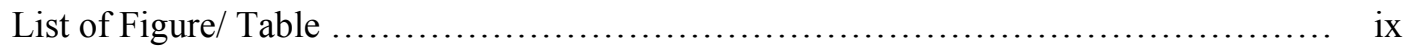

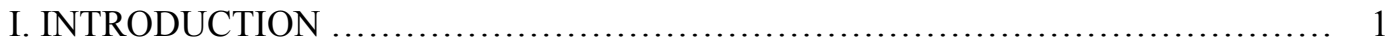

Theoretical Foundation ........................................................... 2

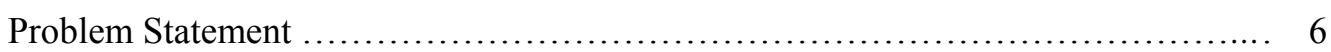

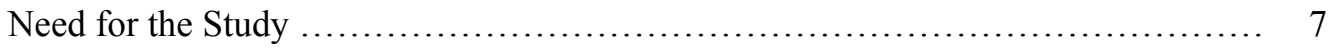

The Purpose of the Study ................................................... 9

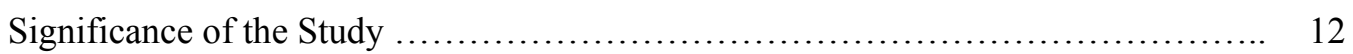

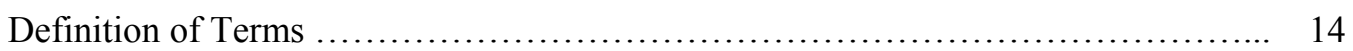

II. REVIEW OF LITERATURE ............................................ 19

Transactional Distance Theory............................................... 19

Review of Research on Transactional Distance Theory........................... 21

Two Studies that Tests the Three Constructs of TDT........................... 22

Studies that Attempted to Refine TDT.................................... 24

Summary: Limitations in TDT and Research ............................ 31

Operational Definition of Transactional Distance and Student Motivation............ 33

Teacher Immediacy ..................................................... 35

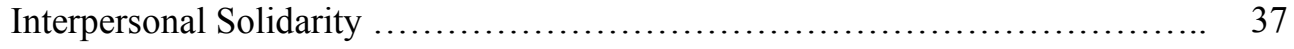

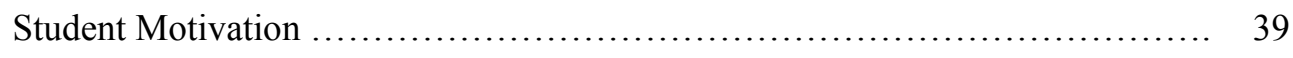

Research Questions...................................................... 40

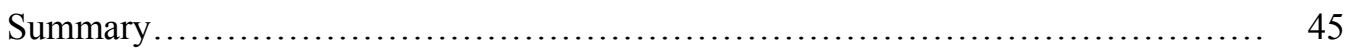




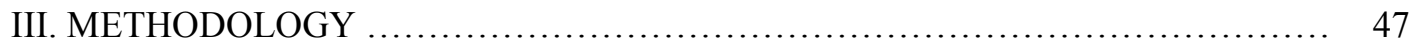

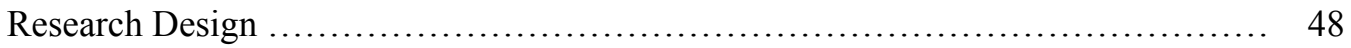

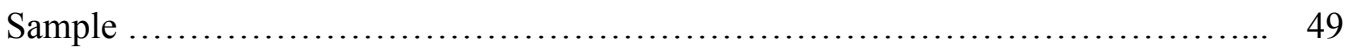

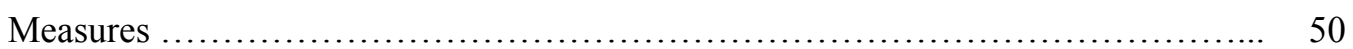

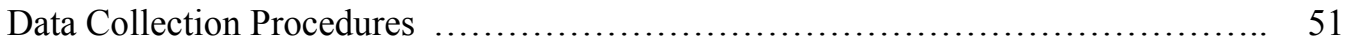

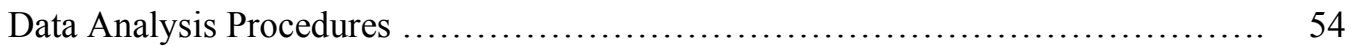

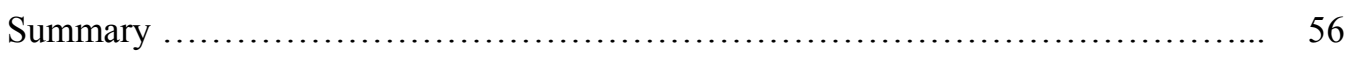

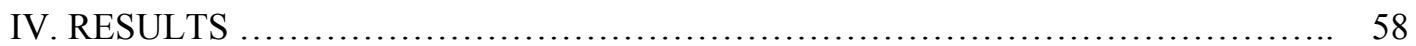

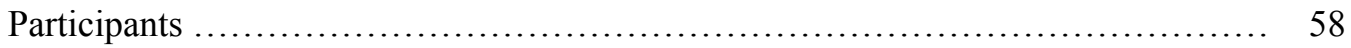

Research Question and Data Analysis.................................... 61

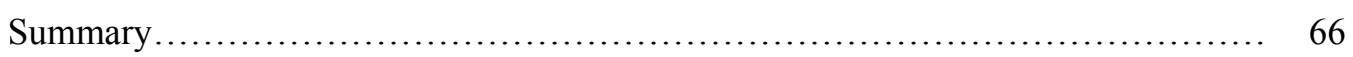

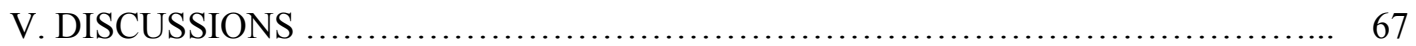

Discussions Related to Research Questions.......................................... 67

Limitations and Directions for Future Research................................ 73

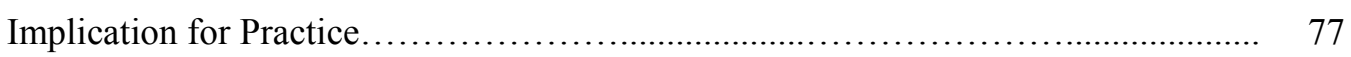

Discussions: Transactional Issues and Communication Variables ................. 79

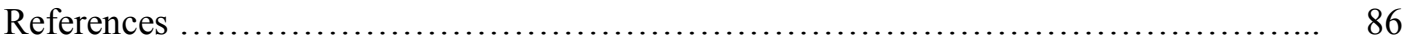

Appendix A Cover Letter to Students ....................................... 95

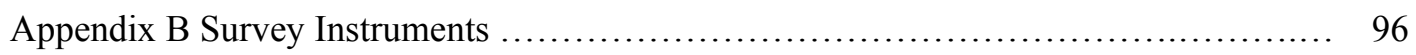

Appendix C Nonverbal Immediacy Scale-Observer Report (NIS-O) ................. 100

Appendix D Student Motivation Scale ........................................ 102

Appendix E Interpersonal Solidarity Scale.................................... 103

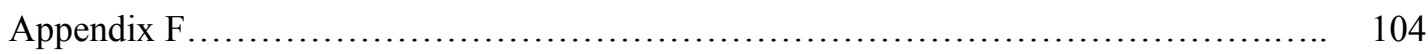

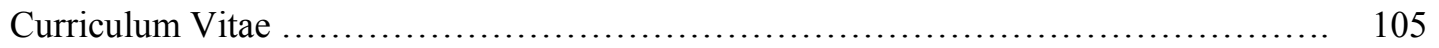




\section{LIST OF TABLE}

Page

Table $1 \quad$ Five Cohorts and Semester. 49

Table 2 Cohort, Location and Number of Students......................... 52

Table 3 Summary of Research Questions, Survey Instruments and Analysis....... 55

Table $4 \quad$ Sampling and Population....................................... 58

Table 5 Demographic Information by Marital Status, Employment, Gender, Age 59

Table $6 \quad$ Nonverbal Immediacy Face-to-Face vs. Remote Classroom....................... 60

Table $7 \quad$ Solidarity toward their Peer Students in The Same Classroom............ 61

Table $8 \quad$ Solidarity toward their Peer Students in the Other Classrooms ............ 62

Table $9 \quad$ Alpha Reliability Estimates, Means, and Standard Deviations for 63

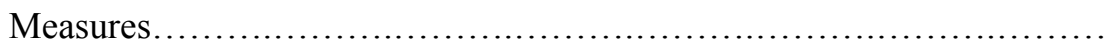

Table $10 \quad$ Nonverbal Immediacy based on Gender............................. 64 


\section{CHAPTER I}

\section{INTRODUCTION}

The history of distance education in the United States can be traced back to the 1800 s when the idea of "distance education" used a correspondence model based on print materials. Today, the term distance education indicates diverse delivery models using various technologies, including print and mail systems, broadcast television, cable TV, interactive TV, recorded audio and video media, teleconferencing, videoconferencing, computer-supported learning, computer conferencing, web-based instructional programs and virtual reality.

The advent of these technologies in distance education challenged educators and researchers to understand the proper applications of distance educational options. Garrison (2000) discussed theoretical challenges for distance education in the $21^{\text {st }}$ century in the following way:

The advent of new technology created conceptual confusion. Recent and rapid technological development raise questions whether distance education theory has kept pace with new, affordable applications of communications technology and the changing educational needs of a learning society (p. 2).

Garrison (2000) reviewed the significant theoretical developments and contributions to the distance education research. The primary focus of distance education research in the $20^{\text {th }}$ century was on "distance constraints and approaches that bridged geographical constrains and approaches that bridged geographical constraints by the way of organizational strategies such as the mass production and delivery of learning packages" (p. 2), and this is regarded as the industrial era of distance education. Garrison 
(2000) argued that the 21 st century will be the postindustrial era "where transactional issues (i. e., teaching and learning) will predominate over structural constraints (i.e., geographical distance)" (p.2). Transactional issues in distance education include sociocultural context, social presence, learner control and interaction (Garrison, 2000). Michael Moore (1993)'s discussion on transactional distance is one of the first transactional issues in the distance education. Moore's (1980) transactional distance theory contributed to a shift from structural to transactional issues in the distance education.

This study has its theoretical foundation the transactional distance theory to investigate different patterns of interaction among students, and between students and teachers in a distance learning environment. This chapter is divided into five sections: theoretical foundation, problem statement, and need for study, the purpose of the study, significance of the study and definitions of terms.

Theoretical Foundation

The theoretical foundation of the current study is transactional distance theory. Before getting into the details of the theory, two major theoretical contributions to distance education, which were predominant in Distance Education in $20^{\text {th }}$ Century, will be discussed: The influential work of Otto Peters and Charles Wedemeyer. The purpose of discussing Peters' industrial model and Wedemeyer's (1971) focus on independent learning is to provide a more holistic picture of the literature in the theoretical developments in distance education. Transactional distance theory was developed based on these two theories. 


\section{Theoretical Development from Structural to Transactional Issues}

The industrial model emerged in the 1960s "during the time when behaviorism was at its height of popularity, together with the related approaches of programmed instruction and instructional systems design (ISD)" (Gunawardena \& McIsaac, 2001, p. 360). According to Gunawardena and McIsaac (2001), the industrial model "emphasizes an instructional unit as products which can be mass-produced and distributed like cars or washing machines" (p.360). The industrial model is one of the major contributions to the field of distance education. Gunawardena and McIsaac (2001) summarized the industrial model in distance education as follows:

Peters characterized distance education as a method of imparting knowledge, skills and attitudes which is rationalized by the application of division of labor and organizational principles as well as by the extensive use of technical media, especially for the purpose of reproducing high quality teaching material which makes it possible to instruct great numbers of students at the same time wherever they live (p. 360).

Wedemeyer (1971), on the other hand, focused on independent study, freedom and choice for the learner, and on equity and access. Wedemeyer's "pedagogical assumption of independent study was a shift from world of correspondence study dominated by organizational administrative concerns, to a focus on educational issues concerning learning at a distance" (Garrison, 2000, p. 5). In that Wedemeyer (1971) clearly focused on learning, his work remains very relevant to current research trends in distance education. 
However, his focus on independent learning as opposed to interdependent or collaborative learning was limited due to the lack of consideration on the interactive nature of more current distance education practices. The recent advent of diverse distance learning environments provided the possibility of both independent and collaborative learning experience.

Moore (1993) recognized limitations of focusing on structure and independent learning. Moore attempted to "incorporate the structure of the industrial approach with the interaction of transactional approach (Garrison, 2000, p.9). The theoretical foundation of this study is transactional distance theory. The concept of transaction was originally derived from John Dewey and was developed by Boyd. Transaction refers to "the interplay among the environment, the individuals, and the patterns of behaviors in a situation between people" (Boyd \& Apps, 1980, p. 5). In distance education, 'transaction' is "the interplay between people who are teachers and learners, in environments that have special characteristic of being separate from one another, and a consequent set of special teaching and learning behaviors" (Moore \& Kearsley, 1996, p. 200). In other words, "the interplay," is adapted patterns of teaching and learning behaviors in the context that teacher and learners are separated. By definition, transactional distance refers to the "psychological space of potential misunderstandings between teachers and learners" (Moore \& Kearsley, 1996, p. 200), due to the "the physical distance that leads to a communications gap" (Moore \& Kearsley, 1996, p. 200). The transactional distance theory is conceptually important since it addresses that the essential distance in distance education is transactional, not spatial or temporal. 


\section{Transactional Distance Constructs}

The transactional distance theory identified dialogue, structure and learner autonomy as the key constructs of the transactional distance. According to Moore (1993), the amount of dialogue and the rigidity of the structure determine the degree of transactional distance between learners and teachers. Dialogue refers to interaction between teacher and students and THAT among students. Structure is "the rigidity or flexibility of the programme's educational objectives, teaching strategies, and evaluation methods" (Moore, 1993, p. 26). Structure has also been defined as 'responsiveness' of programs to an individual learner's needs (Moore \& Kearsley, 1996).

The third construct of transactional distance is learner autonomy. Moore (1990) defined learner autonomy as "the extent to which in a program the learner determines objectives, implementation procedures, and resources and evaluation" (p.13). In this definition, learner autonomy was a similar concept to that of the learner's independent study.

The relationships among these three variables can be summarized as follows:

1. The relationship among structure, dialogue and transactional distance is that the higher the structure is and the lower the dialogue is a more remote transactional distance exists (Moore, 1993). Moore (1993) stated that "when a program is highly structured and teacher-learner dialogue is non-existent; the transactional distance between learners and teachers is high" (p.27).

2. The relationship among structure, dialogue and learner autonomy can be summarized as: "the greater the structure and the lower the dialogue in a program the more autonomy the learner has to exercise" (Moore, 1993, p. 27). 
3. The relationship between transactional distance and learner autonomy: when remote transactional distance exists, the more autonomy the learner has to exercise.

\section{Problem Statement}

\section{Micro-level: Problem with Transactional Distance Theory}

While the transactional distance theory is conceptually significant and foundational theory of transactional issues in post-industry model in distance education, a review of literature identified three problems. First, relations between the three constitutional variables; dialogue, structure and learner autonomy, are ambiguous, and their associations with transactional distance has not been verified. Second, no operational definitions of any kind have been proposed for any of the variables (Gorsky \& Caspi, 2005). Moore $(1993 ; 1996)$ used the various terms (i.e. variable, cluster, constituent) to explain structure and dialogue; however, these terms created confusion in testing the theory. Third, the results of empirical research on transactional distance neither support nor validated the theory. These problems with research on the transactional distance theory are mainly due to the lack of reliable and valid measurements. Each of the previous studies defined transactional distance differently, and adopted different ways of measuring transactional distance.

\section{Macro-level: Problem with Distance Education Research}

The lack of reliable and valid measurements is not limited to the study of transactional distance theory but exists throughout studies on distance education. The research on distance education has received harsh criticism regarding the lack of empirical research, the dominance of descriptive research, and the lack of validity and 
reliability of the instruments used to measure students' experience or learning outcomes in distance education (Chen \& Willits, 1999). Berge and Mrozowski (2001) also argued that research in distance education has been limited by dominantly adopting descriptive methodology and conducting less experimental or correlation research.

Need for the study

One of the challenges discussed in the filed of distance education is "whether theorists should borrow theories from other disciplines to explain distance education or develop unique theories that describe the nature of the field" (Gunawardena \& McIsaac, 2001, p. 359). Garrison (2000) documented theoretical developments in the field of distance education in his seminal article and reported the theoretical development of the field is progressing from organizational to transactional issues and assumptions. In the transactional approach, communication plays an important role. Garrison (2000) argued that placing "real two-way communication at the core of the educational experience, regardless of separation of teacher and student (p. 9)," is "a clear attempt to break loose of the organizational assumptions of the industrial model” (p. 9).

The field of communication studies deals with two-way communication in diverse contexts (instructional, intercultural, cross-cultural, organizational, computer mediated, interpersonal and gender). Communication Studies has developed its discipline based on theories and knowledge borrowed from other disciplinary studies, such as psychology, politics, sociology and education.

The rationale of this study is that the interdisciplinary nature and the accumulated knowledge of the field of Communication Studies could also contribute to other fields of studies. Although distance education is becoming a major focus in higher education, the 
Communication Studies discipline has been less interested than others in researching distance learning modes (Kuehn, 1994). According to Kuehn (1994), communication researchers, lack an interest in researching distance education, computerized instruction, and computer-mediated communication. Guzley and his colleagues (1999) argued that communication researchers should be particularly interested in distance education. Transactional Model of Communication and Transactional Issues in Distance Education

There are dozens of communication models that simplify and represent complex interrelationships among elements in the communication process. Two prominent communication models are the linear model and the transactional model. In 1949, Claude Shannon, a Bell Laboratories scientist, and Warren Weaver, a consultant on projects at the Sloan Foundation, described communication as a linear process. This model was developed with regard to radio and telephone technology, and it explains how information passed through various channels (West \& Turner, 2000).

While the linear model presumes that communication flows from a sender to receiver, the transactional model of communication focuses on the simultaneous sending and receiving of messages and underscores the cooperative process of communication. According to these perspectives, "the sender and the receiver are mutually responsible for the effect and effectiveness of communication" (West \& Turner, 2000, p. 10).

In a transactional undertaking, "people build a shared meaning, rather than a meaning being sent as they do in the linear model" (p. 10). In other words, the transactional model presumes that sender(s) and receiver(s) exchange messages simultaneously, attending to both a message's verbal and nonverbal elements. Features of the transactional model of communication include "a person's field of experience or how 
a person's culture, experiences and heredity influence his or her ability to communicate with another" (West \& Turner, 2000, p. 11).

The Purpose of the Study

As discussed earlier, Transactional Distance Theory is conceptually significant in that the core nature of distance in distance education is not definite geographical or temporal distance but psychological or communicational distance, which can explain the relative quality of experience in the context. In spite of the conceptual significance of the transactional distance theory, the theory was found to be invalid and unreliable. The interrelationships among the construct variables and propositions of the theory are unclear. The majority of studies on transactional distance theory either used the theory solely as conceptual framework or proposed the refinement of the theory. No measurements have been consistently used to measure transactional distance. Lack of valid measurements handicaps the accumulation of academic knowledge in the field.

This study focused on the conceptual significance of transactional theory through the use of concepts and measurements from Communication Studies. This study made efforts to investigate Moore's theory of transactional distance with the concepts of 'immediacy' and 'solidarity,' which are often used in the field of Communication Studies. By doing so, transactional distance theory can represent students' perceptions of others in distance learning atmosphere. The operational definition of transactional distance between teacher and students (TDST) is students' perception of teacher's immediacy behavior and that of transactional distance among students (TDSS) is students' perception of learner. 


\section{Research Design}

The design of the research is based on Jung's (2003) qualitative research. Jung (2003) explored the effect of students' perception of others on their perception of learning in the videoconferencing classroom. Videoconference based classrooms are comparable to traditional classrooms in some ways. They are similar in that all students have real-time communication, including text, audio and video signals. However, they are different in other ways. Interaction between the distant-site students and the onsite participants, students and an instructor, is mediated by technology, which provides some restrictions in the interaction.

Jung (2003) interviewed students and instructor in a simulation course offered in an AACSB accredited MBA program, and revealed that offsite students develop stronger team spirits than students' in on-campus. The off-campus study also found that there are some communication gap between students and teacher. Jung (2003) concluded that offcampus students may develop closer relationship with students in the same site to overcome the lack of direct interaction with their distant site's counterparts and the instructor, and it also may due to the characteristics of adult learners.

Transactional distance discusses psychological distance due to the communication gap in distance education context. Current study looks psychological distance due to the communication gap between students and instructor and that among students. In addition, the study examined how these perceptions are related to students' motivation toward their course work. 


\section{Research Questions}

This study asks four research questions. The first research question (RQ 1) is "to what extent do onsite students and offsite students differently perceive the teacher immediacy?" Examining the different perceptions on the teacher's nonverbal immediacy behavior will directly address the relative nature of psychological distance in opposition to the definite geographical distance issues.

The second research question (RQ 2) involving students' perception of their peer students asks "to what extent do onsite students and offsite students differently perceive solidarity to classmates? The second research question seeks to find out if there is a significant difference between onsite and offsite students in perceiving solidarity toward classmates at same site and remote sites. The second research question (RQ 2) was divided into two:

RQ 2a. To what extent do onsite students and offsite students differently perceive solidarity to classmates in the same site?

RQ 2b. To what extent do onsite students and offsite students differently perceive solidarity to classmates in remote sites (in the other sites)?

The third and fourth research questions deal with students' perception of their motivation toward the course in association with their perceptions toward their instructor (RQ 3) and their peer students (RQ 4). The third research question asks "to what extent is the student perceptions about teacher immediacy related to the student motivation?" The fourth research question (RQ 4) asks "To what extent is the student perceptions about interpersonal solidarity toward their classmates related to the student motivation?" The fourth research question (RQ 4) is divided into two: 
RQ 4a. To what extent are the student perceptions about interpersonal solidarity toward their classmates in the same site related to the student motivation?

RQ 4b. To what extent are the student perceptions about interpersonal solidarity toward their classmates in the remote sites (the other sites) related to the student motivation?

While the traditional corresponding model of distance education or distance education using broadcasting media may have focused on the linear model of communication, today's interactive media may allow the transactional model of communication. In short, there are needs for interdisciplinary research between the fields of distance education and communication studies. In this study, the author focused on the transactional distance theory, which is one of the foundational theories in distance education.

A number of studies on the distance education have generally concluded that there is no significance in the learning outcome of students enrolled in courses through distance education and those in traditional face-to-face classrooms. Theses findings have been referred as the 'no significant difference' phenomenon. Despite these results, there is a lack of reliable explanation for the high drop-out rate of students in many distance education programs and a lack of accumulated knowledge bases about the quality of learning experience in the distance learning setting compared to students in the traditional classroom format.

\section{Significance of the Study}

Transactional Distance Theory is conceptually significant in that it discusses the psychological and communicational space and defined the distance beyond the "spatial or 
temporal" space (Moore, 1993). The relative nature of the psychological or communicational distance will be able to explain the relative quality of experience in the context that they are definitely separated from teacher.

There are a few unique features of this study, which overcome some limitations of distance education research. First, this study is designed based on the transactional distance issues in distance education, which is a foundational theory in the post-industrial view of distance education. Considering that "research that is not grounded in theory is wasteful" (Moore, 1991, p. 2), this study contributes the body of knowledge in the field of distance education.

Second, interdisciplinary approach is adopted to overcome limitations in both fields of distance education and Communication Studies. Based on Moore's transactional distance theory, this study identified communication as core of educational experience in distance education context, and explored the alternate communication model, which can be nested in the transactional distance theory.

Third, this study deals with a total academic program, instead of focusing on an individual course. Guzley and Avanzino (2001) noticed another "notable limitation" of research trends in distant education; namely, its focus on one element of the distance education experience, such as only one vague task, leaving the larger encounter another context unexplored. With regard to this limitation, Phipps and Merisotis (1999) pointed out that current research in distance education emphasizes individual courses rather than across a total academic program. This research overcomes one of most frequently identified limitations in distance education by conducting a program-based study. 


\section{Definitions of Terms}

Several key terms are used throughout this study. Some of key terms include EMBA, Cohort, Videoconferencing, Onsite Students and Offsite Students. EMBA is an abbreviation for Executive Master of Business Administration. The EMBA programs allow working professionals to pursue an MBA degree while moving forward in their careers. The sample of current study was pulled from an AACSB-accredited EMBA program, which hosts several locations in the Mid-Atlantic Region. The EMBA program uses videoconferencing learning atmosphere with five cohorts groups. Executive MBA students begin their program together in a cohort or group, since the collaborative nature of the cohort tends to lower the drop out rate and enhance graduation rate. Each cohort is composed of one onsite group of students and two offsite groups of students. Onsite student groups also have more opportunity to interact with teacher before and after class sessions. Offsite student groups do not have their instructors physically present in their classroom and they interact with their instructors with videoconferencing media and other communication media, telephone, fax and email.

Terms that are relevant to the Transactional Distance Theory include Transaction, Transactional Distance (TD), Transactional Distance between Student and Teacher (TDST), Transactional Distance among Students (TDSS), Dialogue, Structure and Learner Autonomy. Three terms that are from Communication Studies are Immediacy, Solidarity and Students' Motivation toward their course. This study used the concept of teacher immediacy and students' solidarity as the operational definition of the TDST and TDSS. These terms are defined below: 


\section{Definitions from Distance Education}

Distance Education: According to Moore (1993), distance education is "the universe of teacher-learner relationships that exist when learners and instructors are separated by space and/or time" (p.22). This paper argues that the definition of distance education also needs to include student-student relationships. In here, distance education is defined as distance education as the universe of teacher-learner and learner-learner relationships that exist when learners and instructors are separated by space and/or time.

Distance Learning: Distance learning often defined as "structured learning in which the student and instructor are separated by place and sometimes by time" (Gunawardena \& McIsaac, 2001, p.355). In this study, distance learning is defined as the learning that occurs in the distance education contexts instead of focusing on the structured learning.

Videoconferencing: Videoconferencing media include the use of interactive computer networks and audio, video networks that are linked by cable microwave and satellite.

Onsite Students: Onsite Students refers to students on the main campus who have their instructor physically present in the classroom; their learning experience is more similar to that of a traditional classroom setting.

Off-site Students: offsite students whose instructor is not physically present in the classroom; their communication with instructor is mainly through videoconferencing, email, communication tools in Web-Ct, fax and phone. 
Transaction: Boyd and Apps (1980) defined transaction as "the interplay among the environment, the individuals, and the patterns of behaviors in a situation between people." (p.5).

Transactional Distance: The original definition of transactional distance is "a psychological and communications space to be crossed, a space of potential misunderstanding between the inputs of instructor and those of the learner" (Moore, 1993, p. 23). Later Moore redefined transactional distance as “a psychological space of potential misunderstandings between the behaviors of instructors and those of the learners" (Moore and Kearsley, 1996, p.200), especially due to "the physical distance that leads to a communications gap" (Moore and Kearsley, 1996, p.200). In this research, the transactional distance is defined as psychological and communicational distance between instructor and students, as well as among students. In a traditional classroom setting, how close students feel about their instructor has been studied with the concept of immediacy in the discipline of instructional communication studies. Although Moore and Kearsley (1996) stated that transactional distance is due to the physical distance, Moore also stated that that Transactional distance exists in all educational events, even those in a face-to-face classroom setting.

Transactional Distance between Students and Teacher (TDST): a psychological and communicational distance between instructor and students.

Transactional Distance among Students (TDSS): a psychological and communicational distance among students. 
Dialogue: Moore (1993) originally differentiated the dialogue and interaction by defining dialogue as "an interaction or series of interaction having positive qualities that other interactions might not have" (p.24). However, scholars use dialogue as twoway communication between student and teacher and among students that can take the form of synchronous and/or asynchronous distance learning environment (Chen \& Willits, 1998).

Structure: Levels of rigidity of course organization and course delivery (Chen \& Willits, p.1999).

Learner autonomy: "the learner perceptions of both independent and interdependent participation in a learning activity and involves both the learner's ability to learner individually/self-directed and his or her preference or need for collaborative learning" (Chen \& Willits, 1999, p.48).

Media Richness: Media Richness indicates the richness of this kind of media is determined by four characteristics: The relative speed and ease of providing feedback, the range of simultaneous cues that are possible and the extent of personal focus that is possible. According to Rao and Dietrich (1996), the "faceto-face environment is generally considered to have the highest level of media richness" (312), and the interactive video classroom is categorized in the next level.

Affordances: The affordances of media indicates the properties of the medium which afford the means of interaction, including the ability to transmit light to afford qualitative visual interaction and the ability to transmit sound to afford hearing. There are differences in the affordances of video conferencing interaction and 
face-to-face communication, in spite of continuing communication technological advances.

\section{Definitions from Communication Studies}

Immediacy: "a measure of psychological distance, which a communicator puts between himself or herself and the object of his/her communication" (p.363). Immediacy can be conveyed through verbal or nonverbal communication and "immediacy enhances social presence" (p. 363).

Nonverbal Immediacy: operational definition of TDST. Nonverbal Immediacy indicates “students' perceptions of a teacher's physical or psychological closeness by identifying behaviors of approach-avoidance" (p.238).

Nonverbal Communication: "the process of stimulating meaning in the minds of others through nonverbal message, or messages that are nonlinguistic or non-language based" (Richmond \& McCroskey, 2000).

Interpersonal Solidarity: "a feeling of closeness between people that develops as a result of shared sentiments, similarities, and intimate behaviors" (p.223).

Student Motivation Toward their Course: students' general feelings and attitude about their course. Motivation is "a force or drive that influences behavior to achieve a desired outcome” (Millette \& Gorham, 2002, p. 141). While motivated students want to achieve their goals, tend to attend and prepare for class, turn in assignments, ask questions and study for exams; unmotivated students are helpless, defensive, un prepared for, or absent from class, etc (Millette \& Gorham, 2002). 


\section{CHAPTER II}

\section{REVIEW OF LITERATURE}

In order to examine the problem introduced in the previous section, this chapter reviewed literature from two academic disciplines, distance education and communication studies. Distance Education literature addressed mainly on the empirical studies that had dealt with the transactional distance theory. Communication literature focused on the three variables: teacher immediacy, interpersonal solidarity and students' motivation. These three variables were used as the operational definitions of transactional distance between student and teacher, transactional distance between students and student, and motivation toward their course. Based on the review of literature from both distance education and communication studies, four research questions were generated.

\section{Transactional Distance Theory}

Transactional distance theory was first appeared in 1972 and stated that "distance education is not simply a geographic separation of learner and teachers, but, more importantly, is a pedagogical concept" (Moore, 1993, p. 22). The concept of transaction was derived from Dewey (Dewey \& Bentley, 1949), and 'connotes the interplay among the environment, the individuals and the patterns of behaviors in a situation' (Boyd \& Apps, 1980, p. 5). In distance education, the transaction occurs between teachers and learners in the context that they are geographically separated. The geographic separation between teachers and learners profoundly affect both the teaching and learning process, because "there is a psychological and communication space to be crossed, a space of potential misunderstanding between the inputs of instructor and those of the learner. 
(Moore, 1993, p. 23)" This psychological and communication space was defined as transactional distance (Moore, 1993).

Psychological and communications space between any one student and his or her teacher can never be exactly the same. In other words, transactional distance is a relative concept rather than an absolute concept (Moore, 1993). According to Moore (1993), the relative extent of transactional distance is not determined by the geographical distance but by a function of three sets of variables, which are Dialogue, Structure, and Learner Autonomy.

\section{Three Constructs of Transactional Distance}

Dialogue refers to "an interaction or series of interactions having positive qualities that other interactions might not have. A dialogue is purposeful, constructive and valued by each party" (Moore, 1993, p. 24). Moore originally differentiated dialogue from interaction. Moore (1993) stated that "there can be negative or neutral interactions; the term 'dialogue' is reserved for positive interactions, with value placed on the synergistic nature of the relationship of the parties involves" (p. 24). Later, studies used dialogue and interaction interchangeably. Moore (1993) listed a number of factors that influence dialogue and transactional distance, including number of students, teacher personality, learner personality, content, physical and emotional environments and communication media.

Structure refers to "the rigidity or flexibility of the programme's educational objectives, teaching strategies, and evaluation methods" (Moore, 1993, p. 26). Structure also describes how rigid or flexible the program is in responding to the students' individual needs. The extent of structure is determined by "the nature of the 
communication media, the philosophy and emotional characteristics of teachers, the personalities and other characteristics of learners, and other the constraints imposed by educational institutions" (Moore, 1993, p. 26).

Learner autonomy refers to the "extent to which in the teaching/learning relationship, it is the learner rather than the teacher who determines the goals, the learning experiences, and the evaluation decisions of the learning programme" (Moore, 1993, p. 31). The learner autonomy and transactional distance is "The greater the transactional distance, the more such autonomy the leaner will exercise" (Moore, 1993, p. 27)."

The function of dialogue, structure and learner autonomy determines the extent of transactional distance. According to Moore (1993), dialogue and transactional distance are inversely related while structure and transactional distance is proportionately related. Moore (1993) stated the relationship among structure, dialog and learner autonomy as "the greater the structure and the lower the dialogue in a programme the more autonomy the learner has to exercise" (p. 27). In other words, the further transactional distance exists, the more learner autonomy is required for students to be successful in the distant learning environment.

\section{Review of Research on Transactional Distance Theory}

Although transactional distance theory has existed for a considerable time, there are only a few empirical studies that have dealt with transactional distance theory. Two studies (Bischoff, Bisconer, Kooeker \& Woods, 1996; Saba \& Shearer, 1994) focused on Moore's three constituent variables, including dialogue, structure and learner autonomy, and their interrelationship with transactional distance. However, these studies failed to 
find the exact nature of the interrelationships among structure, dialogue and autonomy, and their relationship with transactional distance. Later, seven studies (Chen \& Willits, 1998; Chen \& Willits, 1999, Chen, 2001a; Chen, 2001b; Huang, 2002; Zhang, 2003; Lowell, 2004) have tried to correct this flaw by testing additional variables and redefining transactional distance as a multi-dimensional concept, which led to theoretical refinements of transactional distance theory. Some studies that discussed the concept of transactional distance in connection with other transactional issues (Lally \& Barrett, 1999; Hopper, 2000; Shin, 2001; Weaton et. al, 2003) were also reviewed.

Two Studies that Test the Three Constructs of Transactional Distance Theory (TDT)

Saba and Shearer (1994) empirically examined the relationships among dialog, structure, and transactional distance by using a system dynamics model. The result of the study indicated that transactional distance was a function of structure and dialogue. The study supported Moore's hypothesis that transactional distance decreases when dialogue increases and structure decreases. They also found that increases in learner control increased dialogue and decreased transactional distance. The findings of their study revealed that learner control and dialogue are negatively related to transactional distance.

The methodology that Saba and Shearer (1994) adopted was quite different from other studies. A system dynamics model was used to examine the relationship between dialogue and structure in transactional distance. Cookson and Chang (1995), however, identified limitations of Saba and Shearer (1994)'s study. First, Saba and Shearer's reliance on System of Interaction Analysis limited their study since it led them to focus more on instructors than on the learners. Secondly, the study dealt with the desktop videoconferencing context and limited interaction only between a single student and a 
single instructor. Lowell (2004) also criticized Saba and Shearer's (1994) study:

The characterization of dialog as either active or passive, as in the Saba and Shearer (1994) study, overlooks important characteristics of dialog, such as who can say what and what kinds of messages are permitted. While those characteristics may be part of the structure component, neither Moore nor Saba and Shearer address these important dialogic functions (p. 7).

Bischoff, Bisconer, Kooeker and Woods (1996) investigated students' perceptions of transactional distance in both traditional and distance-format courses delivered via Hawaii Interactive Television service, a two-way audio and full-motion television system. Based on Moore's Transactional Distance Theory, Bishoff et al (1996) conducted a survey based study to find the relationship between dialogue and structure, dialogue and transactional distance, and structure and transactional distance. They also investigated to what extent dialogue and structure predict the transactional distance. Bischoof and her colleague (1996) developed and used a 68-item questionnaire to measure dialogue, structure and transactional distance. The result of their study indicated, that there is an inverse relationship between dialogue and structure, which is consistent with Moore's hypothesis. In comparing traditional and distance-format courses, respondents reported different levels of transactional distance perceived in the process of distance learning. The methodology of Bishoff et al (1996)'s study was limited in that learner autonomy issues were not discussed and that only two items included "closeness and distance between you and the teacher" and "closeness and distance between you and the other learners" in measuring the transactional distance construct. With regard to the validity and reliability of the measurements, the authors assessed internal consistency reliability 
using Cronbach's alpha. To get content validity, the researchers consulted with experts in the field of education.

Chen and Willits (1998) identified limitations of both Saba and Shearer (1994) and Bischoff et al. (1996)'s study. First, both of the studies failed to address learner autonomy, the third constituent of the transactional distance theory. Second, they failed to explore how dialogue, structure and transactional distance are related to student learning. Third, they did not explore other variables affecting dialogue, structure, learner autonomy and transactional distance. In addition, transactional distance was measured with only two items, which asked the degree of closeness or distance students perceived between instructor and learner and that among the learners.

Studies that Attempted to Refine the Transactional Distance Theory

This section reviewed seven studies that attempted to extend or refine the transactional distance theory. The first two studies were done by Chen and Willits (1998, 1999), which explored the multidimensional nature of dialogue, structure and learner autonomy. In the first study, Chen and Willits (1998) extended Moore's theory by adding factors into a path-analytic framework along with indications of dialogue, structure and learner autonomy. According to the study, determinants of perceived learning outcomes and transactional distance include:

1. physical presence of the instructor

2. learner's access to computer and electronic communication software

3. learner's skill, size of the learning group

4. learner's previous experience with video conferencing

5. learner's prerequisite knowledge level of the subject matter 
6. level of courses

These six variables were used as exogenous variables, and dialogue, structure, and learner autonomy were used as mediated variables. The results of the study indicated that:

1. the frequency of in-class discussion was positively related to the physical presence of the instructor and the learner's previous knowledge of the subject matter, while negatively related to the size of the learning groups.

2. transactional distance between the teacher and learner was not related to structure or to learner autonomy.

3. the structure of the course organization and its delivery has little overlap and these are distinct factors.

4. transactional distance among cross-site learners was directly affected only by the in-class discussions.

5. the learner's perceived learning outcome is also directly connected to in-class discussions.

Another study by Chen and Willits (1999) used exploratory factorial analysis, and identified dimensions (factors) constituting dialogue, structure and learner autonomy in the videoconferencing classroom. Findings indicated that dialogue is composed of three dimensions: in-class discussion, out-of-class electronic communication and out-of-class face-to-face interaction. Structure consisted of course organization and course delivery. Learner autonomy was found to be two dimensional, including independence and interdependence. Chen and Willits (1999) reported that most students described themselves as both "independent" and "interdependent" learners.

While Chen and Willits (1998, 1999)'s studies identified multi-dimensions 
constituting dialogue, structure and learner autonomy in the videoconferencing classroom, other studies also looked at the dimensions of the transactional distance. The theory originally referred to transactional distance as a psychological and communication gap between students and teachers in distance learning. However, more recent studies looked at transactional distance not only between students and teacher but also between a student and other students, between students and content and between students and interface. Moore suggested that there are three types of interactions, which are learner-toinstructor, learner-to-learner, and learner-to-content interaction. Hillman (1999) added another pattern of interaction, which is learner-to-interface interaction.

Chen (2001a, 2001b) studied four dimensions of transactional distance, learnerinstructor, learner-learner, learner-content, and learner-interface. The Moore (1993)'s transactional distance theory originally looked at only transactional distance between students and teacher. Chen (2001a) defined learner-instructor transactional distance as "the psychological distance of understandings and communication that learners perceive as they interact with teacher" (p. 462), and learner- learner transactional distance as "the psychological distance of understandings and communication that learners perceive as they interact with other learners" (p. 462). Transactional distance between learner and content involves "the distance of understandings that learners perceive as they study the course materials and the degree that the materials meet their learning needs and expectations to the course" (p. 462). Transactional distance between learner-interface indicates "the degree of friendliness/difficulty that learners perceive when they use the delivery systems" (p. 462).

This approach places communication at the center of the transactional distance. 
Chen (2001a) argues that "of all teaching and learning behaviors, interaction is fundamental to the educational transaction and the effectiveness of distance education programs" (p.460), and consistent to Moore (1989, 1993a)'s approach to the four dimensional interaction. Exploratory factor analysis was carried out and the results showed that transactional distance consisted of four dimensions, as predicted.

Using the four dimensions of transactional distance as dependent variables, Chen (2001b) attempted to extend Moore's theory further. She incorporated four additional determinants of transactional distance, which are (a) skill level in using the internet, (b) previous experience with distance education, (c) learner support, and (d) online asynchronous interaction. The results of the study indicated that only learner's skill level in using the internet and the extent of online interaction had effects on perceived transactional distance. Learners' previous experience with distance education and learner support did not affect transactional distance. Chen (2001b)'s study was based on a fairly small number of cases $(n=71)$ and the results are somewhat argumentative, since learner support has been regarded as one of the factors to decrease drop-out rates.

Huang (2002) attempted to develop a scale to measure students' perceptions of the online courses based on Moore's transactional distance theory, and to measure relationships between students' perceptions and other variables, including age, gender, online course experience and computer skills. The findings of the study are: (a) age was significantly correlated to interaction, course structure and interface dimensions. (b) Online course experience and computer skills have a strong relationship to student perceptions in online learning environment. (c) Computer skills were also correlated with learner autonomy and the interface. (d) There is a strong correlation between learner-to- 
learner interaction and learner interdependence. (e) There is no significant correlation between independence and interdependence in learner autonomy $(\mathrm{r}=.01)$, which means learner independence and interdependence are two separate dimensions.

Zhang (2003) generated four dimensions of transactional distance, which are between student and student (TDSS), between student and teacher (TDST), between student and content (TDSC) and between student and interface (TDSI). The findings of his study indicated that "the strongest factor that affected students' sense of transactional distance and engagement with learning was found to be transactional distance between students and students (TDSS) followed by transactional distance between student and teacher (TDST) and then transactional distance between student and content" (TDSC).

In her dissertation research, Zhang (2003) argued that since Moore's theory of transactional distance was developed in the age of correspondence schools, it needs revision when applied to the web-based learning environment. According to her, the new theoretical model of transactional distance should have four dimensions; transactional distance between student and students (TDSS), transactional distance between student and teacher (TDST), transactional distance between student and content (TDSC), and transactional distance between student and interface (TDST). She invented the scale of transactional distances and administered to a sample of 100 college students. The findings of this study indicated the strongest factor that affected students' sense of transactional distance and engagement with learning was transaction distance between student and students (TDSS), followed by transactional distance between student and teacher (TDST), then TDSC. The author concluded that the result provided strong support for constructivist learning theories and social learning theories, reinforcing the 
importance of establishing learning communities.

More recently, Lowell (2004) attempted to extend Moore's transactional distance theory, measuring the influence of traditional components of the theory, dialogue, structure and learner autonomy as well as three additional variables, context, social presence, and fluency on the transactional distance. Results of the study provided no support for the traditional construction of transactional distance. Dialogue, social presence, and fluency, instead of dialog, structure and learner autonomy, were found to be the only significant predictors on perceived distance.

\section{Transactional Distance and Other Transactional Issues}

Transactional distance theory has become a foundational theory and provides a framework for analyzing other transactional issues. Lally and Barrett (1999), for example, conducted a case study in a computer mediated communication (CMC) atmosphere to explore "the ways in which CMC might reduce the social isolation experienced by some distance learners" (p. 152). Here, social isolation has the similar meaning as "transactional distance," since the goal of this study was summarized as “transactional distance' mediating the academic and social dialogue between distanceeducation students and their tutors" (p. 147). They collected data using electronic diaries, transcripts of online discussions, survey and a focus group interview to investigate an online learning community and the socio-academic nature of such a community.

Shin (2001) investigated the relationship between distance students' perceptions of the presence of teachers, peer students and educational institutions and their learning. The "perception of presence" was defined as the degree to which a distance student senses the availability of and connectedness with each partner and is designated as 
“Transactional Presence (TP)." Shin found that peer students' TP has a stronger relationship with affective learning while teacher's TP has more to do with cognitive learning. For those students involved in out-of-classroom types of distance education, the institution's TP is relatively more important than teachers' TP and students' TP. Shin's (2001) study concluded that TP can be a significant predictor of distance student achievement, satisfaction and persistence.

Wheaton, Stein, Calvin, Overtoom and Wanstreet (2003) examined whether learner interaction led to the development of learning communities, and whether interaction, structure or distance among participants affected learner perceptions of their learning. According to their findings structure and adequate interaction produce greater learning, and structure is the most important factor in the online learning environment. This finding revealed the importance of structure to student satisfaction with learning and reaffirmed the need for instructors to develop clear objectives and activities.

Transactional distance theory has also been studied in connection with sociocultural issues. For example, Hopper (2000) conducted qualitative research focusing on a wide range of variables regarding learner's characteristics and life circumstances, and examined how these factors affect learners' perceptions of transactional distance, learner achievement, and learners' satisfaction in a distance education environment in a two-way video conferencing environment. Two interesting assertions surfaced among the findings. First, while learner characteristics and life circumstances directly affected their participation in the program, they did not have a direct impact on the formation of the learners' perceptions of transactional distance. Secondly, no matter how great the transactional distance was, it was not regarded as an impediment to learner achievement 
or learner satisfaction in the distance learning environment.

Summary: Limitations in Transactional Distance Theory and Research

Transactional distance was first appeared in the 1970s and has been considered one of the traditional theories in the distance education discipline. Since the theory has been around for long time period, a relatively small number of studies were conducted. This study identified nine studies which directly discuss transactional distance theory and another four studies that referred to transactional distance in conjunction with other transactional issues. Among the nine studies on transactional distance theory, only two of them tested the original propositions of Moore's Transactional Distance theory and attempted to find an interrelationship of the three constituent variables, dialogue, and structure and learner autonomy. The other seven studies attempted to refine the theory. Two of the seven studies looked at dimensions (factors) constituting three major concepts of the theory, or dialogue, structure and learner autonomy. Likewise, Chen (2001a, 2001b) studied four dimensions of transactional distance, while the original theory only discusses transactional distance between students and teachers.

Previous studies testing the transactional distance theory have limitations in many aspects. Empirical studies failed to find the interrelationship among the three constructs. In other words, previous studies documented the lack of construct validity of the theory. The definition of the TDT's constructs and Transactional Distance do not have an operational definition, which has been consistently used. Researchers who studied the theory had different operational definitions and different measurements. Especially with dialogue, majority of previous studies focused on the number of communications while according to Moore's own definition; dialogue is not the number of verbal interactions. 
The operational definitions of TD have been measured only between teacher and students, in the earlier studies. However, later some studies looked at TD as two-dimensional between students and teacher, among the students, and some looked at TD as fourdimensional TDST, TDSS, TDSI and TDSC. The current study looked at the role of communication in the context and the learners perception of others regarding how close they perceive about their teacher and their peer students. Not only is there no consistent operational definition, but also no reliable measurements.

The fundamental rationale for the current study is a belief that Moore's theory is logically inconsistent in its explanation of the relationship among the three determinants; dialogue, structure and learner autonomy. Gorsky and Caspi (2005) reviewed published empirical studies on the transactional distance theory and concluded that the basic proposition of transactional distance theory were neither supported nor validated. The interrelations among construct variables and transactional distance are ambiguous and none of them have operational definitions that have been consistently used in testing the theory. The study did not focus on the propositions of the transactional distance theory since the theory has never been a valid scientific theory. Gorsky and Caspi (2005) suggested that the concept of transactional distance needed to be operationally define with concept of "student misunderstanding," and should be measured with percentage of misunderstanding. Assuming the extent of transactional distance is equivalent to the extent of student misunderstanding and measuring it as a percentage does not support the original definition of transactional distance. The concept of transactional distance represents the relative nature of psychological and communication space in opposition to the definite concept of the geographical distance in the distance education context. 
Previous studies, even with variance, attempted to measure transactional distance with the level of closeness/distance students perceive not the percentage of their misunderstanding.

In addition, measuring transactional distance with the percentage of potential student misunderstanding does not provide a reliable measure when studying transactional distance. Bishoff et al (1996)'s study was limited in that only two items included "closeness and distance between you and the teacher" and "closeness and distance between you and the other learners" in measuring the transactional distance construct. Measuring transactional distance with the percentage of potential student misunderstanding is not really different from some of the previous studies which used only one or two items to measure transactional distance. In the next section, this study provides an operational definition of transactional distance with the concepts of teacher immediacy and interpersonal solidarity. Both measured these two communication concepts with the 26-item likert scale of Richmond, McCroskey and Johnson (2003)'s Nonverbal Immediacy Scale-Observer Report (NIS-O) and a 20 item likert scale of Interpersonal Solidarity. These measurements have a record of high reliability and validity from previous studies. The nonverbal Immediacy Scale-Observer Report (NIS-O) measures of psychological distance, which a communicator puts between himself or herself and the object of his/her nonverbal communication cues. The interpersonal solidarity scale measure a feeling of closeness between people.

Operational Definition of Transactional Distance and Student Motivation Chen (2001b) suggested that "further research may consider alternative measures for assessing transactional distance" (p. 337). In this section, immediacy, solidarity and 
motivation will be discussed. The conceptualization immediacy and solidarity in communication studies manifest how close or distant people feel the person they interact with. These two concepts are adopted to use as the operational definition of transactional distance and to provide alternative measures for assessing transactional distance. Student motivation is reviewed to find if perceived transactional distance affects student motivation toward their course.

Communication variables are selected based on the three reasons.

1. No valid measurements exist in studying transactional distance. Previous studies used one or two items to measure transactional distance in their self-developed survey instruments. These items basically ask students how close or distant they feel toward their instructor and their peer students.

2. The literature review indicated that interaction is a core construct variable of the transactional distance. Chen (2001a), for example, argues that "of all teaching and learning behaviors, interaction is fundamental to the educational transaction and the effectiveness of distance education programs" (p. 460).

3. The Communication Studies discipline has accumulated research in the educational context and these can be utilized in distance education. Instructional communication scholars look at the process of instruction as a "manifestation of applied communication" and saw "teaching as communication and much of pedagogical theory as applied communication” (Richmond \& McCroskey, 1992, p. ix).

Transactional distance theory is more global than others and there is "room for more finely focused, molecular theory within the framework provided by a more molar 
theory" (Moore 1993, p. 23). In this study, communication theories of nonverbal immediacy and interpersonal solidarity were reviewed to rationalize integrating communication theories and concepts in studying transactional distance. In addition, it is reviewed how these concepts can be related to student motivation toward course. Teacher Immediacy: Transactional Distance between Teacher and Students (TDST)

Previous studies defined transactional distance between students and teacher as how close/distant students feel toward their instructor. In instructional communication studies, the students' perception of psychological distance between teacher and students has received a great deal of attention in the traditional classroom. Immediacy was conceptualized as teacher's verbal and nonverbal behaviors that either increases or decreases the degree of psychological distance (Anderson, 1979; Gorham, 1988). Gunawardena and McIsaac (2003) defined immediacy as "a measure of psychological distance, which a communicator puts between himself or herself and the object of his/her communication" (p. 363).

Immediacy can be conveyed through verbal or nonverbal communication (Gunawardena \& McIsaac, 2003). In verbal communication, what people say can make us feel either closer or distant from them and immediate verbal messages show openness, friendship, or empathy to the other. On the other hand, as your verbal immediacy decreases, you have distanced yourself from the other person and decreased the likelihood of a significant relationship or may even build a negative one. Nonverbal message can be communicated through eye contact, space, touch, body movement and gesture, voice, time and environment (Richmond, 2002). When we like somebody we are likely to stand closer listen more attentively, have more eye contact, perhaps even touch. 
On the other hand, if we do not like or even dislike somebody, we tend to lean away from that person, have little eye contact, remain silent and not touch, unless it is to abuse the person. In other words, people communicate our feelings through our nonverbal behaviors with forms of approach and avoidance behavior. We would like to avoid the person we dislike, while we are likely to approach or allow someone to approach, if we like them. In the instructional context, previous studies have found that teacher immediacy behavior is positively associated with students' cognitive learning and positive student evaluation of teachers (Richmond \& McCroskey, 2000).

Although immediacy can be communicated through both verbally and nonverbally, the nonverbal components may be more important in most cases. According to Richmond (2002), nonverbal messages often exist independent of verbal messages and "if a verbal message suggests immediacy while nonverbal messages are contradictory, receivers tend to disregard the verbal and respond to the nonverbal (p. 68). Since teacher's nonverbal immediacy behavior has more significance in communicating immediacy, this study focuses on perceived nonverbal immediacy in defining transactional distance between student and teacher (TDST). This study defined transactional distance with communication variables, nonverbal immediacy and interpersonal solidarity, not only to focus on the conceptual foundation of transactional distance but also to utilize more reliable and valid measurements from communication studies.

Nonverbal immediacy is conceptualized through the development of the nonverbal immediacy measures. Most measurements of nonverbal immediacy have been developed through Janis F. Anderson's two instruments: Andersen's Generalized 
Immediacy (GI) scale and Behavioral Indicants of Immediacy (BII). Andersen proposed the construct of nonverbal immediacy in education, which outgrew the work in the interpersonal arena (McCroskey \& Richmond, 1992).

Andersen's Generalized Immediacy (GI) scale consists of nine semantic differential-type items, which measure the overt level of teacher immediacy. The behavioral Indicants of Immediacy (BII) scale is an observational methodology for measuring immediacy levels of teachers. BII scale consists of 15 Likert type items, which measure teacher's behavior such as gestures, eye contact and smile.

Richmond, Gorham and McCroskey (1987) modified BII and developed the Nonverbal Immediacy Behaviors instrument and further modified it to the abbreviated 10 items scale. To increase reliability and validity of the scale, Richmond, McCroskey and Johnson (2003) updated the instruments again and introduced a 26-item scale, Nonverbal Immediacy Scale-Observer Report (NIS-O) and Nonverbal Immediacy Scale - self-report (NIS-S). This study adopted the Nonverbal Immediacy Scale-Observer Report (NIS-O) to focus on student's perception of teacher's immediacy behavior.

Interpersonal Solidarity: Transactional Distance between Student and Student (TDSS)

Interpersonal solidarity refers to "a feeling of closeness between people that develops as a result of shared sentiments, similarities, and intimate behaviors" (Wheeless, 1976). The perceived transactional distance between any individual student toward his or her peer students, interpersonal solidarity was used as an operational definition of the transactional distance between students and teacher.

Wheeless (1976) conceptualized the Interpersonal Solidarity Scale based on the Roger Brown's concept of interpersonal solidarity, which addresses "being close or 
remote, near or far, the in-group versus the out-group" (Brown, 1965, p. 57). According to Brown (1965), a feelings of closeness in a high solidarity relationship can be established with persons such as "brothers and sisters, lovers, spouses, close friends, comrades in arms, school fellows" (Brown, 1965, p. 58). Participants of cohort groups often describe their cohort as being like a family (Lawrence, 2002).

Wheeless, Wheeless and Dickson- Markman (1982) modified the Interpersonal Solidarity Scale to measure the closeness of relationships of group members with each other. Wheeless et al (1982) studied the relations among social and task perceptions in small groups. Cohesion is one of the key concepts reflecting the social dimension of small groups. According to Wheeless et al (1982), conceptualization of cohesion is similar to the interpersonal solidarity construct, and they stated "a common denominator of both solidarity and cohesion is increased closeness among members" (p. 375). They argue that "utilizing solidarity as representative of social-affective dimension permits the integration of indicants of affect found in the literature, such as liking, attraction, trust, psychological closeness, and so on" (p. 375). Wheeless et al (1982) used a group solidarity measure and found the moderately strong correlations among the task variables and group solidarity. Since there is lack of a valid measure of group satisfaction and cohesion, "the group solidarity measure could be considered a good measure of cohesion or the social-affective dimension of group" (p. 182).

The Wheeless (1976)'s first version of the interpersonal solidarity consisted of 10 items, 9 of which formed a scale with high internal consistency. Factorial analysis indicated the 9-item scale is a unidimensional measure. Wheeless (1976) also found that the solidarity scale has closer association with items tapping love, trust and frequency of 
interaction than the self-disclosure scale. In other words, Wheeless's study validated solidarity measures as social closeness of the relationship.

Wheeless (1978) expanded the 9 items solidarity measurement with 12 additional closeness items 'to provide a fuller sampling of the criterial attributes constituting the content of the concept of interpersonal solidarity" (p. 150). "Factor analysis of the expanded interpersonal solidarity scales produced an unrotated unidimensional solution." Only one item did not load appropriately and the 20 -item measure of interpersonal solidarity was produced. The scale had a reliability of .96. Wheeless (1978) found that both self-disclosure and individualized trust are criteria attributes of solidarity.

While closeness of the relationship is the dominant attribute of interpersonal solidarity other affective components contribute to the overall construct: perceptions and sentiments similar to attraction, trust, and credibility; interpersonal similarities and perceptions of communalities; frequent interaction, disclosing communication; private communication, symbolic expressions of solidarity, and interpersonal understanding or empathy" (p. 155).

Since solidarity is a conceptually rich higher order-concept which encompasses trust, attraction, liking, similarity and the others, not much research has been done using the concept. It has been studied with valid and reliable instrument, and the concept was used for the operational definition of transactional distance among the students.

\section{Student Motivation}

Motivation is "a force or drive that influences behavior to achieve a desired outcome" (Millette \& Gorham, 2002, p. 141). While motivated students want to achieve their goals, tend to attend and prepare for class, turn in assignments, ask questions, study 
for exams, unmotivated students are helpless, defensive, unprepared for, or absent from class, etc (Millette \& Gorham, 2002). Motivation can be divided into two types: primary and secondary motivation. Primary motivational dispositions are unlearned, which include motivation to address bodily needs of food, sleep, sex, insurance against pain and danger, the need for acceptance and belonging, feelings of self-confidence, and the need for self-actualization (Millette \& Gorham, 2002).

Secondary motivation on the other hand, refers to drives that have been learned. According to Millette and Gorham (2002), secondary motivation can be either extrinsic or intrinsic. Extrinsic motives occur when there are extrinsic rewards and punishments or because of some value associated with the activity. For example, a student practices because the piano his or her parents want him/her to do so, or to win a piano competition. Intrinsic motivation arises from one's own needs. For example a student may choose to read a book for personal pleasure. These secondary motives, however, is dependent on their relationship with primary, unlearned primary drives.

Student motivation is important because it is related to students' learning. Teachers use many communication behaviors to motivate students. One of them is teacher immediacy behavior, which is a direct motivator of students. An immediate teaching style is viewed by students as more positive and effective, which increase student affect toward the teacher and course.

\section{Research Questions}

This study attempted to measure transactional distance between student and teacher, and transactional distance between student and student by operationally defining transactional distance with two communication variables nonverbal immediacy and 
interpersonal solidarity. This study questioned if there is significant difference between students who have their teacher physically in their classroom (RQ 1) and those who do not have in perceiving psychological and communication distance toward their teacher and toward their peer students (RQ 2). In addition, the study questioned how these perceptions of psychological distance related to student motivation toward their course (RQ 3; RQ 4). This section discusses the development of research questions.

\section{RQ 1: Transactional Distance between Teacher and Students (TDST)}

In communication studies, teacher immediacy has been studied in relationship to student learning for the past two decades, and teacher immediacy behaviors have been found to be associated with student learning. Plax, Kearney, McCroskey, and Richmond (1986), for example, concerned with the role of power in the classroom and verbal behavior-alteration techniques (BATs), suggested that "although immediacy and use of BATs each had unique impact on students' affective learning, the overwhelming majority of the impact of BATs was found to be mediated by immediacy" (McCroskey \& Richmond, 1992, p.105).

Immediacy has been explored by DE scholars. According to Hackman and Walker (1990), distant learners perceive teachers' immediacy behaviors through interactive television, and the instructors' use of nonverbal cue, such as providing individual attention, maintaining a relaxed body posture and using various vocal uses, can contribute a more satisfying learning experiences for distant learners. Murphy et al. (1993) argued that the incorporation of immediacy behaviors which communicate interpersonal closeness and convey approachability should be part of the infrastructure that provides the interactive television system. 
Freitas, Myers and Avtagis (1998) investigated whether perceptions of instructor immediacy differ between students enrolled in conventional and distributed learning classrooms. They found a significant difference between the groups in perceiving instructor nonverbal immediacy, while no significant difference was found in perceived instructor verbal immediacy.

Carrell and Menzel (2001) designed three experimental settings: a live face-toface classroom, a video conferencing classroom, and audio with a PowerPoint display classroom. They found a significantly high perceived instructor immediacy for students in live the classroom compared to the other two distance education settings. (They used Generalized Immediacy and state motivation instruments.) Both Carrell and Menzel (2001) and Freitas, Myers and Avtagis (1998) consistently yield results indicating that onsite students have higher perceived immediacy toward their instructor than off-site students. The null hypothesis of the first research question is:

RQ 1: To what extent do onsite students and offsite students differently perceive teacher immediacy?

Interpersonal Solidarity: Transactional Distance between Student and Student (TDSS)

Souder (1993) evaluated the effectiveness of distance education in comparison to the traditional classroom setting in a satellite delivery course. Souder (1993) discussed "kindred spirit," a concept which is similar to transactional distance among students. The findings indicated that offsite students have more maturity, a sense of responsibility and feeling of a "kindred sprit" with other distance learners. These students also performed better on exams than students in the traditional classroom setting. Huang (2002) argued that "some learning takes place beyond the instructor's scope, for example, in discussions 
and in collaboration with peer learners" (p.31). This research question is also testing Jung (2003)'s results. Jung found that students at off-campus more frequently use the words like “our team" or “our cohort.” The conclusion of Jung (2003)'s study indicated that while offsite students do not have teacher in their classroom, they may compensate the physical absence of their teacher with solid team development with their peer students at their site. Jung (2003) quoted one student in off-campus as shown below:

Strength is that you truly become a team, because the teacher is not there. In a traditional classroom, it is not about team effort, it is about the professor teaching you as an individual. Because the professor is not in the classroom, it creates team effort that we as the $\mathrm{W}$ cohort try to help teammates solve the problem. So, that is the strength. That makes us a bond as a group (p.1576).

Based on Jung (2003)'s study, the current study tested quantitatively to find whether students in remote sites may compensate their lack of direct interaction with their classmates in their site.

RQ 2a: To what extent do onsite students and offsite students differently perceive solidarity to classmates in the same site?

RQ 2b: To what extent do onsite students and offsite students differently perceive solidarity to classmates in remote sites (in the other sites)?

\section{Transactional Distance and Student Motivation}

Teacher immediacy helps to increase students' attention, build confidence and improve satisfaction, which are necessary conditions for student motivation. Immediate teacher move about the classroom, make eye contact, use vocal variety, address students by name, all of which are attention getting. Use of immediacy behaviors may also help to 
build confidence in students. An immediate teacher seems to produce liking and positive feeling among students, which creates an environment where successes may seem more likely.

Frymier (1994) also found that students with an immediate teacher tend to be more satisfied with their learning experience than students with a low immediacy teacher, because teacher immediacy helps to increase motivation because of their positive impact on attention, confidence, and satisfaction. The results of Christophel (1990)'s study also indicated that immediacy may modify motivation that leads to increased learning.

RQ 3: To what extent are the student perceptions about teacher immediacy related to the student motivation?

Huang (2002) argued that "some learning takes place beyond the instructor's scope, for example, in discussions and in collaboration with peer learners" (p.31). Souder (1993) evaluated the effectiveness of distance education in comparison to the traditional classroom setting in a satellite delivery course. Souder (1993) studied "kindred spirit," among students in the distance education program. Souder (1993) found that kindred sprit is similar to the transactional distance among offsite students.

Communication behavior is an indicator of psychological distance between people. According to Kilgore (1999), a sense of solidarity motivates individuals to participate in the collective learning process (p.199). Jones-Delcorde (1995) argues the lack of direct interaction between teacher and students in the distant education context can be another source of motivation. According to him, students in distant site can be encouraged "to dig a little deeper into available resources and through this process 
emerge as a more independent and motivated learner, capable of self-instruction, a trait in which contemporary employers are very interested" (28).

RQ 4a. To what extent are the student perceptions about interpersonal solidarity toward their classmates in the same site related to the student motivation?

RQ 4b. To what extent are the student perceptions about interpersonal solidarity toward their classmates in the remote sites (the other sites) related to the student motivation?

\section{Summary}

This chapter reviewed TDT literature ad identified consistent limitations in studying the theory. The literature reviewed indicated that majority of the previous studies on transactional distance were either focused on the variables that affect the transactional distance or their interrelationship. However, the literature review identified three major limitations of previous studies on transactional distance. First, there is no operational definition that was adopted for each of important concepts of the theory and no measurements were consistently used. Second, no studies have validated the interrelationship among the dialogue, structure and learner autonomy and their relationship with transactional distance. Third, dialogue, structure and learner autonomy should not be considered as constitutional variables for transactional distance theory.

In order to examine the problem introduced in the previous section, this chapter reviewed literature from two academic disciplines, distance education and communication studies. The first part of literature review mainly addressed empirical studies that are based on transactional distance theory and transactional issues. The 
second part of literature review focused on three communication variables, which are teacher immediacy, interpersonal solidarity and students' motivation. 


\section{CHAPTER III}

\section{METHODOLOGY}

The current study has dual purposes. First, this study attempts to investigate if there is significant difference between students in main campus and students The second purpose is to examine if students perception of their teachers and peer students are related to the students motivation toward the course. The questionnaire and data analysis were designed to answer the following research questions. Four research questions guided this study.

RQ1. To what extent do onsite students and offsite students differently perceive teacher immediacy?

RQ 2a. To what extent do onsite students and offsite students differently perceive solidarity to classmates in the same site?

RQ 2b. To what extent do onsite students and offsite students differently perceive solidarity to classmates in remote sites (in the other sites)?

RQ3. To what extent are the student perceptions about teacher immediacy related to the student motivation?

RQ 4a. To what extent are the student perceptions about interpersonal solidarity toward their classmates in the same site related to the student motivation?

RQ 4b. To what extent are the student perceptions about interpersonal solidarity toward their classmates in the remote sites (the other sites) related to the student motivation?

The review of method includes research design, descriptions of the sample of students, measures and instrumentation, data collection procedures and data analyses. 


\section{Research Design}

A survey based quantitative methodology was designed to examine the four research questions posed in chapter one. Although the research design is quantitative, the study originated from a small scale qualitative study (Jung, 2003) that was part of the author's graduate course work. The qualitative study allowed for a close examination of the perceptions of learners' and that of instructor's in the EMBA program. Based on the findings of Jung (2003)'s study, Moore's transactional distance theory was integrated into research questions to induce the big picture of students' perception in the context. Communication studies were

The survey-based design was used to get students perception of teacher immediacy, interpersonal solidarity toward peer students and student motivation toward their course. The perceived immediacy was used the operational definition of transactional distance between teacher and student, and The study assumes that the level of perceived transactional distance or psychological distance is mainly affected by the interpersonal interactions or communication behaviors, even though communication may not account for entire transactional distance issues.

The EMBA program adopted videoconferencing technology, which allows full interaction between classes originating from Morgantown with students at remote sites using a terrestrial digital telephone line. These technologies permit the college to meet the needs of many regions' working professionals by allowing access to higher education for their career.

The setting of this study creates a "natural experiment" that directly compares students in a traditional classroom and those in a distance classroom. Students in five 
different groups have been in the program in five different durations. Souder (1993) explained that a natural experiment does not refer a designed experiment but presents itself with the virtue of the circumstances. A quantitative methodology and survey-based, exploratory and natural experiment design were adopted to examine the research questions.

\section{Sample}

The samples for this study are drawn from 167 students who are enrolled in an AACSB accredited Executive MBA (EMBA) program.

\section{Description of Cohort}

Students enter the program as members of a student cohort in which students take all classes through the duration of the program with the same classmates. The Executive program provides a fully integrated Interactive Videoconferencing technology, which all interactive real-time video and voice. There are five cohort groups in the program, and each of them has one onsite group, and one or two offsite students' group(s). Most of students of the Executive MBA program are business professionals and want to maintain momentum in their career while pursuing your Executive MBA degree. The classes are offered in both weekend and evening format.

Table 1

Five cohorts and Semester

\begin{tabular}{llllll}
\hline Cohort & Semester I & Semester II & Semester III & Semester IV & Semester V \\
\hline BLM 05 & Spring 2003 & Fall 2003 & Spring 2004 & Fall 2004 & Spring 2005 \\
CMP 05 & Fall 2003 & Spring 2004 & Fall 2004 & Spring 2005 & Fall 2005 \\
CMP 06 & Spring 2004 & Fall 2004 & Spring 2005 & Fall 2005 & Spring 2006 \\
MMW 06 & Fall 2004 & Spring 2005 & Fall 2005 & Spring 2006 & Fall 2006 \\
EMM07 & Spring 2005 & Fall 2005 & Spring 2006 & Fall 2006 & Spring 2007 \\
\hline
\end{tabular}


The program has an explicit emphasis on teamwork. The degree requires 48 credit-hours, which are presented over a two and one-half year period with five term semesters. As shown in Table 1, each year one new cohort joins and one cohorts group graduate from the program. Each semester, each of the five cohort groups takes three courses, which is offered in sequence.

\section{Measures}

Three measures were adopted to answer the research questions; Nonverbal Immediacy Scale-Observer Report, Interpersonal Solidarity Scale and Student Motivation Scale. The operational definition of transactional distance between teacher and student is teacher immediacy and measured with Nonverbal Immediacy Scale-Observer Report. As discussed earlier, students' perception of nonverbal immediacy behavior of teachers can be a good indicator of students' psychological distance toward the teacher.

The operational definition of transactional distance between is interpersonal solidarity toward peer students in the same site and interpersonal solidarity toward peer students in the other sites (remote sites) and measured with Interpersonal Solidarity Scale since students' perception of interpersonal solidarity toward their can be a good indicator of students' psychological distance toward their peers. Richmond (1990)'s Student Motivation Scale is used to measure students' motivation level toward their courses.

Nonverbal Immediacy. Richmond, McCroskey and Johnson (2003)'s Nonverbal Immediacy Scale-Observer Report (NIS-O) is the most up-to-date measure Richmond, Gorham, and McCroskey (1987)'s Nonverbal Immediacy Behaviors (NIB) instrument, which assessed students' perceptions of a teacher's physical or psychological closeness by identifying behaviors of approach-avoidance, such as gestures, movement and eye 
contact (Rubin, Palmgreen \& Sypher, 1994). Nonverbal Immediacy Scale-Observer Report (NIS-O) has higher Alpha reliability estimates around .90 than that of the Nonverbal Immediacy Behaviors (NIB) instrument, estimated ranging from .73 to .89 . NIS-O also has more face validity than previous NIB instrument because it has more diverse items. Its predictive validity is also excellent.

Interpersonal Solidarity. Interpersonal solidarity is a feeling of closeness between people, and it develops as a result of shared sentiments, similarities, and intimate behaviors (Wheeless, 1976; Rubin, Palmgreen \& Sypher, 1994). The Interpersonal Solidarity Scale has been used to measure group solidarity and teacher solidarity (Rubin, Palmgreen \& Sypher, 1994). Wheeless (1978) reported split-half reliabilities of .96 and .94, and Bell and Healey (1992) reported an alpha of .90 for a 19-item scale. With regard to validity, there is sufficient evidence of concurrent and criterion-related validity from previous studies.

Student Motivation. Student Motivation was operationalzed with Richmond's (1990) motivation scale which consists of five it items. Seven-step bipolar items were used with reference to the statement, "please circle the number toward either word which best presents your feelings about your course." The five items includes: motivatedunmotivated, excited-bored, uninterested-interested, involved-uninvolved, and dreading it- looking forward to it. The reliability of this scale in Richmond (1990)'s study was the alpha co-efficient of .94.

\section{Data Collection Procedures}

The director of the program was contacted in advance to obtain permission for administering the questionnaire. After the departmental examination of the summary of 
current study proposal, the faculty members in the executive MBA program decided to support the study. The director advised to post the survey on the program's Web-CT. Each of the five courses sampled was asked to check what semester they are in and how long they have been in the program, which allowed the courses of the respondents to be identifiable, even though individual respondent identification was not collected. Table 1, in previous page, shows the duration and cohort and table 2 represents the number of the population based on the cohort and locations. Main campus students are about two third of the population $(n=91 ; N=167)$ and about a third $(n=76 ; N=167)$.

Table 2

Cohort, location and number of students

\begin{tabular}{|c|c|c|c|}
\hline Cohort Name & Locations & $\begin{array}{r}\text { Number of students } \\
\text { in each site }\end{array}$ & $\begin{array}{r}\text { Number of students in each } \\
\text { cohort }\end{array}$ \\
\hline \multirow[t]{3}{*}{ BLM 05} & Beckley & 7 & 35 \\
\hline & Lewisburg & 18 & \\
\hline & Morgantown & 11 & \\
\hline \multirow[t]{3}{*}{ CMP 05} & Charleston & 6 & 36 \\
\hline & Morgantown & 8 & \\
\hline & Parkersburg & 21 & \\
\hline \multirow[t]{3}{*}{ CMP 06} & Charleston & 12 & 34 \\
\hline & Morgantown & 18 & \\
\hline & Parkersburg & 4 & \\
\hline \multirow[t]{3}{*}{ MMW 06} & Martinsburg & 10 & 33 \\
\hline & Morgantown & 18 & \\
\hline & Wheeling & 5 & \\
\hline \multirow[t]{3}{*}{ EMM07 } & Elkins & 8 & 29 \\
\hline & Morgantown & 16 & \\
\hline & Moorefield & 5 & \\
\hline \multirow[t]{2}{*}{ Total } & Morgantown & 91 & 167 \\
\hline & Remote Sites & 76 & \\
\hline
\end{tabular}


The data were collected through both online and classroom meeting. Initially, the data was going to be collected electronically using Web-CT for two week long period in the end of the semester. However, the EMBA program undertook the system change, and the electronic data collection was not allowed until the next semester. Even when survey was online, the response rate was so low since many students were not familiar with the upgraded system, Web-Vista, and students were so busy with their course work in the beginning of the semester. Students are contacted to recruit participants for the survey through the departmental list-serve system in the beginning of the semester, but due to the low participation rate, the current researcher also had classroom meeting to solicit survey participation. Many students indicated to the current researcher that they did not even open the email and many of them did not even aware that they got the email. Most of the students are employed and they receive so many emails everyday. In addition, many students wanted paper based survey instead of the online-based survey. Due to the students' request and low response late, current study combined both online and in-class data collection. Students were asked to complete a series of instruments regarding the instructor's classroom nonverbal immediacy behavior, perceptions of interpersonal solidarity toward peer students and motivation toward course.

The physical classroom environment varied from site to site with regard to arrangement of furnishings and the specific technology involved. Usually, the main campus site has been more up-to-date with technology and technical support, compared to the distant sites. 


\section{Data Analysis Procedures}

Statistical analysis for this research question consists of descriptive, Independent Samples T-test, Mann Whitney and Pearson's Coefficient of Correlation. The statistical significance level was set at $\mathrm{p}<0.05$ for this study (Alpha for all analyses was .05 ). The following Table 4 and descriptions detail the statistical analyses that were employed to answer the research questions. For missing items in a scale, if there was only one or two missed over 20 items, the average of the other items of the subscale was plugged in.

Independent Samples T-test is used to answer the first research question, which asks if the population means are the same for the on campus and off-campus students in perceiving teachers' immediate behaviors. Since the results of the descriptive data analysis indicated that the mean score of the students' perception of teacher's nonverbal immediacy behavior has normal distribution, Independent Samples T-test was chosen to compare students in main campus and students in distant sites.

The second research question has two sub-questions. The first asks if there is significant difference between main campus students and remote site students in perceiving students in the same sites. The second research question asks if there is difference between the two groups in perceiving students in remote sties. The results of the descriptive data analysis indicated that the mean score of the students' perception of peer students in the same classroom does not have normal distribution, Mann Whitney test was chosen to compare the two groups. The mean score of the students' perception of peer students in the remote sites, on the other hand, found to have normal distribution. Therefore, T-Test was adopted to compare main campus students and remote site students. 
The third and fourth research question used Pearson's Coefficient of Correlation is used to measure if there is significant association between perceived nonverbal immediacy and perceived course motivation and between perceived solidarity toward their peer students and course motivation. To answer third research question, Pearson's Coefficient of Correlation between students' motivation toward course and students' perception on the teacher's nonverbal immediacy behavior was measured. To answer fourth research question, Pearson's Coefficient of Correlation between students' motivation toward course and the level of students' perception on interpersonal solidarity toward other students in their site will be examined.

Table 3

Summary of research questions, survey instruments and analysis

\begin{tabular}{|c|c|c|}
\hline Research Question & Instrumentation & Data Analysis \\
\hline $\begin{array}{l}\text { 1. To what extent do onsite students and distant } \\
\text { site students perceive differently the nonverbal } \\
\text { immediacy of their instructor(s)? }\end{array}$ & $\begin{array}{l}\text { Nonverbal Immediacy } \\
\text { Scale- Observer Report } \\
\text { (NIS-O) }\end{array}$ & $\begin{array}{l}\text { Independent } \\
\text { Samples T-test }\end{array}$ \\
\hline $\begin{array}{l}\text { 2a. To what extent do onsite students and distant } \\
\text { site students perceive differently solidarity to } \\
\text { students in the same site? }\end{array}$ & $\begin{array}{l}\text { Interpersonal Solidarity } \\
\text { (Modified) }\end{array}$ & $\begin{array}{l}\text { Mann Whitney } \\
\text { test }\end{array}$ \\
\hline $\begin{array}{l}\text { 2b. To what extent do onsite students and distant } \\
\text { site students perceive differently solidarity to } \\
\text { other students in the other sites? }\end{array}$ & $\begin{array}{l}\text { Interpersonal Solidarity } \\
\text { (Modified) }\end{array}$ & $\begin{array}{l}\text { Independent } \\
\text { Samples T-test }\end{array}$ \\
\hline $\begin{array}{l}\text { 3. To what extent are the students' perceptions } \\
\text { about their instructor's nonverbal behavior } \\
\text { related to the students' course interest levels? }\end{array}$ & $\begin{array}{l}\text { Richmond's (1990) } \\
\text { motivation scale }\end{array}$ & $\begin{array}{l}\text { Bivariate } \\
\text { Correlation }\end{array}$ \\
\hline $\begin{array}{l}\text { 4. To what extent are the students' perceptions } \\
\text { about interpersonal solidarity toward their peer } \\
\text { students related to the students' course interest } \\
\text { levels? }\end{array}$ & $\begin{array}{l}\text { Richmond's (1990) } \\
\text { motivation scale }\end{array}$ & $\begin{array}{l}\text { Bivariate } \\
\text { Correlation }\end{array}$ \\
\hline
\end{tabular}




\section{Ethical Consideration}

Institutional Review Board (IRB) exempted for the protection of human subjects. A consent and information form was sent to their email account. In classroom meeting, students are also informed in person or through two way video and audio. Students are informed that there were no known or expected risks from participating in this study and that their participation is voluntary.

\section{Summary}

This chapter summarized the method of the study. A survey based quantitative methodology was designed to examine the four research questions. The samples consisted of 79 students who are enrolled in an AACSB accredited Executive MBA (EMBA), which represented for about thirty percept of the population $(\mathrm{N}=167)$. The EMBA program adopted videoconferencing technology, and it created a research opportunity of "natural experiment" that directly compares students in a traditional classroom and those in a distance classroom. Transactional distance between teacher and student was operationally defined with concept of and measured with teacher immediacy and adopted Nonverbal Immediacy Scale-Observer Report for the measurement. A student's perception of transactional distance toward other students was operationally defined with concept of interpersonal solidarity and measured with teacher immediacy and adopted Interpersonal solidarity scale for the measurement. This study adopted Richmond's (1990) motivation scale to measure the correlations between student motivation and students' perception of transactional distance. The data were collected through both online and classroom meeting. The statistical significance level was set at 
$\mathrm{p}<0.05$ for this study (Alpha for all analyses was .05). The data was analyzed using statistical test of significant difference and Bivariate Correlation. 


\section{CHAPTER IV}

\section{RESULTS}

The results of this study are presented by describing demographic information of the participants, reviewing the data analysis to answer the research questions, discussing additional findings and limitations of the study. The current study attempted to find whether there was a significant difference between students on a main campus and offcampus students in perceiving immediate behavior of their instructors and interpersonal solidarity toward peer students at their site and at a distant site. In addition, the study examined how the different perceptions are associated to students' motivation toward their course.

\section{Participants}

The participants for this study were sampled from five cohort groups of an AACSB accredited Executive MBA (EMBA) program, which utilized videoconferencing technology as their delivery tool. Students entered the program as members of a student cohort in which students take all classes through the duration of the program with the same classmates. Each of the five cohorts had one on-campus and two distant site students' groups. Instructors for the each cohort are present at the main campus classrooms, while remote site students use videoconferencing, email, and telephone.

The EMBA degree requires 48 credit-hours, which are scheduled across over two and one-half years with five semesters. Each semester students take three courses for nine credit hours. Instead of taking all three courses at once, students are given three different courses in sequence, which divides a semester into three periods. Of 167 students in executive MBA program, 79 students were sampled. 
Forty four (57\%) students were enrolled at the main campus classroom, and thirty eight (38\%) students were enrolled in the remote classroom $(n=75)$. The distribution of the sampling across the five cohorts and locations are shown in Table 4. The sample size of third and fourth cohort $(n=22 ; n=22)$ are twice as much as first, second and fifth cohort sample size $(\mathrm{n}=11 ; \mathrm{n}=12 ; \mathrm{n}=11)$.

Table 4

Sampling and Population

\begin{tabular}{|c|c|c|c|c|c|}
\hline Cohort Name & Locations & $\begin{array}{l}\text { Sample } \\
\text { in each } \\
\text { location }\end{array}$ & $\begin{array}{l}\text { Sample in } \\
\text { each cohort }\end{array}$ & $\begin{array}{r}\text { Population } \\
\text { In each } \\
\text { location }\end{array}$ & $\begin{array}{r}\text { Population } \\
\text { In each } \\
\text { cohort }\end{array}$ \\
\hline \multirow[t]{3}{*}{ CMP 05} & Charleston & 3 & 11 & 7 & 36 \\
\hline & Morgantown & 7 & & 18 & \\
\hline & Parkersburg & 1 & & 11 & \\
\hline \multirow[t]{3}{*}{ BLM 05} & Beckley & 1 & 12 & 6 & 35 \\
\hline & Lewisburg & 1 & & 8 & \\
\hline & Morgantown & 10 & & 21 & \\
\hline \multirow[t]{3}{*}{ CMP 06} & Charleston & 7 & 22 & 12 & 34 \\
\hline & Morgantown & 10 & & 18 & \\
\hline & Parkersburg & 2 & & 4 & \\
\hline \multirow[t]{3}{*}{ MMW 06} & Martinsburg & 7 & 22 & 10 & 33 \\
\hline & Morgantown & 11 & & 18 & \\
\hline & Wheeling & 3 & & 5 & \\
\hline \multirow[t]{4}{*}{ EMM07 } & Elkins & 3 & 11 & 8 & 29 \\
\hline & Morgantown & 6 & & 16 & \\
\hline & Moorefield & 2 & & 5 & \\
\hline & Total & 78 & 78 & 167 & 167 \\
\hline Missing & & 1 & 1 & 0 & 0 \\
\hline Total & & 79 & 79 & 167 & 167 \\
\hline
\end{tabular}

As indicated in Table 5, the average age of participants was thirty four, and more than half of them were married. Most of the students were employed $(n=65 ; 82.3 \%)$ or 
self-employed ( $\mathrm{n}=5 ; 6.3 \%) .76$ out of 79 students were Caucasian, and highly educated. More than half of the students had a bachelor's degree, and more than a third of the students had either a master's or a doctoral degree.

Table 5

Demographic Information by marital status, employment, gender, age and education

\begin{tabular}{llr}
\hline Demographic Categories & Classification of demographic & \# of \\
& information & students \\
\hline Main Campus vs. Remote Sites & Main campus & 45 \\
$(\mathrm{n}=75)$ & Remote site students & 30 \\
\hline Marital Status & Married & 45 \\
$(\mathrm{n}=77)$ & Single & 25 \\
& Widowed & 7 \\
\hline Employment & Employed & 65 \\
$(\mathrm{n}=77)$ & Self-employed & 5 \\
& Unemployed & 7 \\
\hline Gender & Male & 47 \\
$(\mathrm{n}=78)$ & Female & 31 \\
\hline Age & $23-27$ & 21 \\
$(\mathrm{n}=74)$ & $28-32$ & 18 \\
& $33-41$ & 19 \\
& $42-53$ & 16 \\
\hline Education $(\mathrm{n}=79)$ & Associate degree & 6 \\
& Bachelor's degree & 41 \\
& Master's degree & 18 \\
& Doctoral degree & 8 \\
\hline
\end{tabular}

As indicated table 5 in previous page, Male students $(n=47)$ are a little more than female students $(n=31)$. The age of students ranges from 23-53. In short, the demographic 
information indicated the sample of this study has strong adult learners' characteristics; majority of them are married and have full-time occupation and has higher education.

Research Question and Data Analysis

RQ1: Students’ Perceptions of Teachers’ Nonverbal Immediacy Behavior

RQ1 asked if there were significant differences in students' perceptions of teachers' nonverbal immediacy behavior in onsite and distant site classrooms. Since students' perception of the instructors' nonverbal immediacy behavior showed a normal distribution, a parametric measurement was used. As shown in Table 6, no significant mean difference was found between the students in onsite and remote sites in perceiving teachers' nonverbal immediacy behavior $(\mathrm{t}(74)=-1.617 ; \mathrm{p}=.11$ (two-tailed); $\mathrm{df}=72$ ). Students onsite $(\mathrm{M}=93.898, \mathrm{SD}=11.145)$ reported perceiving less teacher immediacy than students at distant sites $(\mathrm{M}=98.19 ; \mathrm{SD}=11.32)$.

Table 6

Nonverbal Immediacy Face-to-face vs. Remote Classroom

\begin{tabular}{ccccccc}
\hline Variable & $\begin{array}{c}\text { Face-to-face } \\
\text { Classroom } \\
\text { mean }\end{array}$ & $\begin{array}{c}\text { Remote } \\
\text { Classroom } \\
\text { Mean }\end{array}$ & t-Value & Sig. & df & $\begin{array}{c}\text { Mean } \\
\text { Difference }\end{array}$ \\
\hline Nonverbal & 93.8977 & 98.1817 & -1.617 & .11 & 72 & -4.29 \\
Immediacy & $(\mathrm{SD}=14.56)$ & $(\mathrm{SD}=11.00)$ & & & & \\
Behavior & & & & & & \\
\hline
\end{tabular}

*equal variances' assumed

RQ2: Students' Perceptions of Solidarity toward Peer Students

Solidarity toward peer students in same site. Research question two asked if there are significant differences in perceiving solidarity toward their peer students in the same site and peer students across sites. Since students' perception of peer students in the same site behavior did not show a normal distribution, a non-parametric measurement was used. As 
shown in Table 7, results of the Mann-Whitney Test indicated a significant difference when comparing students and the distant sites with regard to their perceptions of solidarity toward their classmates in the same classroom $(\mathrm{M}-\mathrm{W}=412 ; \mathrm{Z}=-2.491 ; \mathrm{p}=$ $0.013)$.

Table 7

Solidarity toward their Peer students in the Same Classroom

\begin{tabular}{llllll}
\hline Variable & $\begin{array}{l}\text { Face-to-face } \\
\text { Classroom } \\
\text { Mean rank }\end{array}$ & $\begin{array}{l}\text { Remote } \\
\text { Classroom } \\
\text { Mean rank }\end{array}$ & $\begin{array}{l}\text { Mann- } \\
\text { Whitney U }\end{array}$ & Z & Sig. \\
& 31.31 & 43.77 & 412 & $-2.491^{*}$ & 0.013 \\
\hline $\begin{array}{l}\text { Solidarity toward students in } \\
\text { the same site }\end{array}$ & & & & & \\
\hline
\end{tabular}

$* p<.05$

Solidarity toward peer students in the remote sites. The second hypothesis tested if there is a significant difference between onsite students and distant site students in perceiving solidarity toward students across sites. The study failed to reject null hypothesis that there is a significant difference between onsite students and distant site students in perceiving solidarity toward students across sites. Since the distribution of student perception of the solidarity toward students across sites was normal distribution, parametric analysis was conducted.

Table 8

Solidarity toward their Peer students in the other classrooms (remote sites)

\begin{tabular}{lcccccc}
\hline Variable & $\begin{array}{l}\text { Face-to-face } \\
\text { Classroom } \\
\text { mean }\end{array}$ & $\begin{array}{l}\text { Remote } \\
\text { Classroom } \\
\text { Mean }\end{array}$ & t-Value & Sig. & df & $\begin{array}{l}\text { Mean } \\
\text { Difference }\end{array}$ \\
\hline $\begin{array}{l}\text { Solidarity toward } \\
\text { students in the }\end{array}$ & 65.45 & 61.34 & 1.179 & .242 & 71 & 4.1052 \\
other sites & & & & & & \\
\hline
\end{tabular}


As shown in Table 8, the results of the 2-way independent samples t-test indicated no significant difference when comparing students in campus and distant sites with regard to their perceptions of solidarity toward their classmates in the same classroom $(\mathrm{t}$ $(72)=-1.179 ; p=.24$ (two-tailed); df=71).

\section{RQ3: Perceptions on the Teacher's Nonverbal Immediacy and Students' Motivation}

The null hypothesis for the third research question is that there is no significant relationship between students' perceptions of the teacher's nonverbal immediacy behavior and students' course interest level. Students' perceptions of instructor's nonverbal immediacy behaviors indicated that there is no significant correlation with students' motivation toward the course $(\mathrm{r}=.201 ; \mathrm{p}=.079 ; \mathrm{n}=78)$.

RQ4: Perception of Solidarity toward Peer Students and Motivation toward Course

The first null hypothesis of the fourth research question is that there is no significant relationship between students' perceptions of interpersonal solidarity toward same site students and students' motivation toward the course. The result of the correlation analysis indicate that there is no significant association between solidarity toward peer students in the same site classroom and motivation $(r=.148 ; p=.206 ; n=75)$. Solidarity toward peer students in distant sites and motivation

The second null hypothesis of the fourth research question asks students' perceptions of interpersonal solidarity toward distant site students and its relationship with students' motivation toward the course. The results of the data analysis indicated no significant association between solidarity toward peer students in distant site classrooms and motivation $\quad(r=.136 ; \mathrm{p}=.194 ; \mathrm{n}=76)$. 


\section{Additional Findings}

Additionally, the data file was splited into the scores of onsite students and offsite students and Bivariate Correlation analysis among variables were conducted. Significant associations were found for onsite students in perceiving solidarity toward same site classmates and solidarity toward remote site classmates $(\mathrm{n}=42 ; \mathrm{r}=.474, \mathrm{p}=.002)$. However, no significant associations were found for offsite students in perceiving solidarity toward same site classmates $(n=30)$ and solidarity toward remote site classmates $(n=29 ; r=.092$, $\mathrm{p}=.634)$.

In scoring nonverbal immediacy, the mean score for females students' perceptions of nonverbal immediacy behavior $(\mathrm{M}=96.7)$ is a little higher than male counterparts' $(\mathrm{M}=91.6)$. If the score is above 112 for female and 106 for male, it is considered as high immediacy, while if it is lower than 81 for female and 77 for male, it is considered as low immediacy. The result of this study, as shown in Table 10, indicates both male and female students have medium high score for the perception of teacher's nonverbal immediacy behavior.

Table 10

Nonverbal Immediacy based on Gender

\begin{tabular}{lllll}
\hline \multicolumn{3}{c}{ Men } & \multicolumn{2}{l}{ Women } \\
\hline Nonverbal & Mean & SD & Mean & SD \\
Immediacy & 91.6 & 9.89 & 96.61 & 12.87 \\
\hline
\end{tabular}

Students' perception of solidarity toward distance students are much lower than $(m=64 ; n=77)$ that toward students in the same class $(m=94.635 ; n=76)$. Significant moderate relationship between solidarity toward their peer students in the same 
classroom and solidarity toward students in distance site $(r=.293 ; p=.011)$. Results of the Mann-Whitney indicate a significant difference when comparing

$(\mathrm{M}-\mathrm{W}=302.5 ; \mathrm{Z}=-2.7 ; \mathrm{p}=0.006)$

Alpha reliability

When using Likert-type scales, it is imperative to report Cronbach's alpha (Gliem \& Gliem, 2003) to find out if there is good internal consistency of the items in the scale. George and Mallery (2003) provide the range of acceptable to unacceptable alpha size. They indicated as: “_> 9 - Excellent, _> $.8-$ Good, _> .7- Acceptable, _> .6Questionable,_>.5-Poor, and _ $<.5-$ Unacceptable" (p. 231). Table 9 indicates that interpersonal solidarity toward same site students has excellent reliability $(\mathrm{r}=.925)$, interpersonal solidarity toward the other site students has good reliability $(\mathrm{r}=.853)$ and student motivation measure has acceptable reliability $(\mathrm{r}=.784)$. The reliability of Nonverbal Immediacy Scale- Observer Report (NIS-O) is found to have good reliability. Table 9

Alpha Reliability Estimates, Means, and Standard Deviations for Measures

\begin{tabular}{lclc}
\hline Name of Measure & Reliability & Means & S. D. \\
\hline $\begin{array}{l}\text { Nonverbal Immediacy Scale- Observer } \\
\text { Report (NIS-O) }\end{array}$ & .869 & $95.36(\mathrm{n}=78)$ & 11.24 \\
$\begin{array}{l}\text { Interpersonal Solidarity toward } \\
\text { classmates in the same site }\end{array}$ & .925 & $94.64(\mathrm{n}=76)$ & 19.52 \\
$\begin{array}{l}\text { Interpersonal Solidarity toward } \\
\text { classmates in remote sites }\end{array}$ & .853 & $64.38(\mathrm{n}=77)$ & 14.56 \\
\begin{tabular}{l} 
Student Motivation \\
\hline
\end{tabular} & .784 & $25.85(\mathrm{n}=78)$ & 5.520 \\
\hline
\end{tabular}




\section{Summary}

This chapter has presented the demographic profile of sample, results from each of the statistical tests that were computed to answer each of the four research questions with six hypotheses. The results of research question one and two, which compared mean difference between onsite and offsite students in perceiving transactional distance, were presented in tabular form followed by written explanation. The results of research question three and four, which explored the relationship between students' perceived transactional distance and student motivation toward their course. Alpha reliability estimates of each of the scale were reported to show the internal consistency of the items in each of the scales employed in this study. The end of the chapter also provided additional findings of the study. 


\section{CHAPTER V \\ DISCUSSION}

The discussion is divided into four sections. The first section summarizes the discussions related to research questions. The second section discusses limitations and directions for future research, the third section suggests implications for practice and the fourth section provides discussions regarding Transactional Issues and Communication Variables.

\section{Discussions Related to Research Questions}

The purpose of this research was to determine if there is any significant difference between onsite and offsite students in perceiving their instructor and peer students, and how students' perceptions are associated with students' motivation toward their courses. Four research questions addressed this inquiry and a quantitative survey based research yielded the results. The first two questions examined if there are mean differences between onsite and offsite students in perceiving distance/closeness toward their instructor (RQ 1) and peer students (RQ 2). The next two questions asked if there is a significant association between students' psychological distance and students' motivation toward their course. The third research question regards students' perception of psychological distance toward their instructor and students motivation toward their course (RQ 3). The fourth research question regards students' perception of psychological distance toward their peer students and students' motivation toward their course (RQ 4). Students' perception solidarity toward peer students was divided into solidarity toward peer students in their site and peer students across sites. Research question two and research question four, therefore, have two hypotheses, respectively. 


\section{RQ1: Students’ Perceptions of Teachers’ Nonverbal Immediacy Behavior}

RQ1 asked if there were significant differences in students' perceptions of teachers' nonverbal immediacy behavior in onsite and offsite classrooms. No significant differences were found between onsite and offsite students in perceiving teacher's immediacy behavior $(\mathrm{t}(74)=-1.617 ; \mathrm{p}=.11$ (two-tailed); $\mathrm{df}=72$ ).

The findings were inconsistent with earlier investigations. For example, both Carrel and Menzel (2001) and Freitas, Myers and Avtagis (1998) reported that students onsite (main campus) perceive higher immediacy toward their instructor compared to students offsite. Offsite students do not have the physical presence of the instructor at their site and the communication between teacher and students, through videoconferencing media, are limited. Mazur (2000) also indicated the problem with responsiveness and interaction in interactive video classrooms. According to his observation, students at the remote sites, where the instructor is not present, often feel ignored. To solve the problem, he proposed using classic film theory and cinematic techniques to be applied in the interactive video classroom.

Videoconference based classrooms are comparable to traditional classrooms in some ways. They are similar in that all students have real-time communication, including text, audio and video signals. However, they are different in other ways. Interaction between the offsite students and the onsite students, students and an instructor, is mediated by technology, which provides some restrictions in the interaction.

Another major reason for failing to find significant difference might have been due to the characteristics of the sample. While previous studies sampled undergraduate students, the current study sampled from executive MBA students, who are adult learners 
and who may not be as sensitive to teachers' immediacy behavior as undergraduate students. Teachers use many communicational strategies to solicit students' cooperation in the teaching process. Often these are related to issues of teachers' control or power over students in the traditional classroom. One of the strategies is immediacy behavior. The adult learners may have a stronger sense of self and may not be affected by teacher's immediacy behavior or other kinds of communication behavior which can be employed by teachers to control them. The physical presence of the teacher might be more important to the undergraduate students since they may need more control in their learning process in the classroom.

RQ2: Students' Perceptions of Solidarity toward Peer Students

Research question two asked if there are significant differences in perceiving solidarity toward their peer students in the same site and peer students across sites. The question two is divided into two. First one (RQ 2a) asked students' solidarity toward classmates in the same site and second one (RQ 2b) asked solidarity toward classmates in remote sites.

The result of the first part of research question two (RQ 2a) indicated there is significant difference between onsite students and offsite students in perceiving solidarity toward same site students $(\mathrm{M}-\mathrm{W}=412 ; \mathrm{Z}=-2.491 ; \mathrm{p}=0.013)$. Off-campus students had much higher solidarity toward students in the same site (mean rank=43.77) compared to the students on the main campus (mean rank=31.31).In contrast, the result of the second part of research question two (RQ 2b) indicated that there is no significant difference between onsite students and offsite students $(\mathrm{t}(72)=-1.179 ; \mathrm{p}=.24$ (two-tailed); $\mathrm{df}=71)$. In short, while perceived solidarity toward students in the same site significantly differs 
between onsite and offsite students, solidarity toward students in the other sites (across sites) did not show any significant differences.

With regard to the findings on solidarity toward students in the same site (RQ 2a), it can be explained that offsite students compensate for the lack of direct interaction with a teacher by their interaction with peer students in their site. This is relevant to Chen and Willits (1998)'s study, which found a significant relationship between the teacher's physical presence in the classroom and the interaction between teacher and students. Souder (1993) also argued that students in distance learning contexts develop a "kindred spirit" that indicates high interpersonal cohesion among the students. Souder's study found that students prefer interacting with peer students without the involvement of the instructor in online discussion.

Although the first null hypothesis of the second research question was rejected, the potential TYPE I Error should be considered. In a statistical test, TYPE I Error occurs when significant finding is defeated even thought in reality it does not exist.

Type I Error Rate is computed using the formula:

$$
\begin{aligned}
1-(1-\alpha)^{\mathrm{c}} \text {,where: } & \\
\alpha & =\text { level of significance } \\
\mathrm{c} & =\text { number of independent } \mathrm{t} \text {-tests }
\end{aligned}
$$

In this study, the level of significance in this study is $\alpha=.05$, and two T-test and one Mann Whitney test was used. Therefore, the possibility of Type I error rate is 0.14 or $14 \%$. In other words, this study has a $14 \%$ of chance in falsely report the significant mean difference. Findings revealed that although offsite students perceive significantly 
higher solidarity toward their peers in the same sites, offsite and onsite students do not have significant differences in perceiving students in the other classrooms.

RQ3: Perceptions on the Teacher's Nonverbal Immediacy and Students' Motivation

This study did not reveal a positive relationship between students' perception of teachers' immediacy behavior and students' motivation toward their course $(r=.201$; $\mathrm{p}=.079 ; \mathrm{n}=78$ ). This may be due to the characteristics of the sample of this study. The data was collected from an executive MBA program. Most executive MBA students have strong characteristics of adult learners; they have full time jobs, are married and are highly motivated.

Lieb (1991) summarized Malcom Knowles's characteristics of adult learners. According to Knowles, adult learners are autonomous and self-directed, have accumulated a foundation of life experiences and knowledge, which need to be connected to learning for a better learning outcome. Adults are also goal-oriented and upon enrolling in a course, they know what they want to attain, whether they are to nurture social relationships, to achieve higher status in a job, to relieve boredom, to satisfy an inquiring mind, or to comply with the expectations of someone with formal authority. Adult learners differ from undergraduate students since they have clear goals for their education, and they enrolled in the course by choice and they tend to find relevance of their learning with their work. EMBA students have more opportunities to apply what they learn from class to their work, while undergraduate students may not have those. This study did not reveal a positive relationship between students' perception of transactional distance toward their instructor, or teacher immediacy, and students' motivation toward their course is due to the sample of this study. The participants of this 
study have strong characteristics of adult learners who are highly motivated, and this may result in failing to reject the null hypothesis of this research question. This assumption is supported by Millette and Gorham (2002), who indicated that "highly motivated students maintained their level of motivation independent of the teacher's immediacy level; however, students initially reporting low or moderate motivation increased their motivation only when exposed to highly immediate teachers" (p.149). In short, this study failed to find significant association between students perception of teacher immediacy behavior and student motivation toward the course. However, the result might have been affected by the fact that the participants of this study are highly motivated adult learners. Studies with undergraduate sample may produce significant association between perceived teacher immediacy and student motivation.

\section{RQ4: Perception of Solidarity toward Peer Students and Motivation toward Course}

No significant association has been found between students' solidarity toward peer students and student motivation toward their course. The first null hypothesis of the fourth research question is that there is no significant relationship between students' perceptions of interpersonal solidarity toward same site students and students' motivation toward the course and the no significant association between solidarity toward peer students in the same site classroom and motivation was found $(r=.148 ; \mathrm{p}=.206 ; \mathrm{n}=75)$. The second null hypothesis of the fourth research question asks students' perceptions of interpersonal solidarity toward distant site students and its relationship with student motivation toward the course. No significant association between solidarity toward peer students in distant site classrooms and motivation $(r=.136 ; p=.194 ; n=76)$ was found. 
Similar to the rationale for adopting research question three, research question four expected that when students perceive others psychologically closer, they would have more motivation toward their course and their learning. As discussed in chapter II, there was some evidence that would support a significant association between student solidarity and student motivation toward their course. Kilgore (1999), for example, argued that a sense of solidarity motivates individuals to participate in the collective learning process. Jung (2003) quoted one offsite students; "because the professor is not in the classroom, it creates team effort that we as the $\mathrm{W}$ cohort try to help teammates solve the problem" (p. 1576). In addition, this study assumed when students have built solidarity with their peer students, it would affect students' motivation toward their course in distance education. The main cause of high drop-out rates of distant learners has been considered to be because students feel isolated with lack of direct interaction with their teacher and classmates. This study assumed the psychological distance among the participants in distance learning would decrease students' feeling of isolation and increased student motivation toward their course. However, it overlooked the fact that motivation involves many factors and this study might be limited to identify the solidarity and Motivation relationship, in distance learning environment. Future research should consider the limitations of this study to develop more solid research to test transactional issues in distance learning environments. In next session, limitations and directions for future research will be discussed.

\section{Limitations and Directions for Future Research}

This study is exploratory in nature because none of the previous studies attempted to integrate the scholastic work of communication studies to test transactional distance 
theory. The review of previous studies indicated that there were no operational definitions that were constantly used, no reliable and valid measurements to test the transactional distance theory. This study sought to overcome the limitations by operationally defining the transactional distance with similar concepts from communication studies. With its experimental nature and interdisciplinary approach, this study has a number of limitations but these suggest avenues for future studies

The first limitation focuses on research design. As discussed in chapter III, this study used the natural experimental design in which the context of study is not modified for the purpose of the study but used the existing natural setting. Therefore, the study could not control variables such as different personality variables of teachers and students, the content of the courses and size of class.

In experimental research design, you can focus on the variables you are testing while controlling irrelevant variables. Future studies may examine the effects of students' perception of transactional distance on students' motivation toward their course in a more experimental design so that it can control external variables as well as claim the causal relationship among variables. For example, by controlling sample size and the content delivered for the study, the interaction among students and students' motivation toward the particular lesson will be more accurately measured.

Other possibilities with research design may include considering a mixed design study, which strengthens the argument of the use of the communication variables as operational definition of the variables in the transactional distance theories. This study attempted to test Jung (2003)'s findings with survey based quantitative research and transactional distance theory. A Mixed study may serve better to test the research 
questions since it allows the methodological triangulation and provides more in-depth understanding of the phenomenon as well as gives opportunity to generalize the findings to broader population. For example, an ethnographic approach would provide a clear picture of students' perceptions of psychological distance toward their instructor and peer students and how it would affect students' learning process; a survey would generalize this perception in connection to the existing theory. In a mixed study, the quantitative portion often permits strengthening the findings of the qualitative research findings by providing applicability to the wider population.

The second direction for future research focuses on instrumentation. The instrument used in this survey includes the interpersonal solidarity scale, the nonverbal immediacy measurement and student motivation scale. All of these measures yielded a high reliability and validity records in previous studies. In this study, the interpersonal solidarity, the nonverbal immediacy measure and motivation measures had above average reliability. It is also recommended for future study to choose proper instruments with existing high reliability and validity records from previous studies and to conduct a pilot test or a validity test and a reliability test to find the appropriateness of the instrument.

The third direction for future research focuses on quality control in data collection. The sample size of this study is relatively small, which may have resulted in the lack of power to reject the null hypotheses. About $35 \%(n=79)$ of population $(\mathrm{N}=169)$ was sampled. When studying the adult learners with high demanding full time jobs and family affairs, it is important to keep the survey item short and implement it when students have relatively lower workloads. Working with faculty members in the program and giving credit or rewards may work better. In the case of this study, the 
quality control in data collection was challenged due to the unexpected system change university wide. The initial schedule of data collection was modified and the data was collected through both online and face-to-face settings. It is also recommended that future studies should consider with quality control in data collection process especially when they conduct the study in the non-controlled context.

The fourth direction for future research addresses different distance education systems. Research questions of the current study were examined in the videoconferencing context. ISDN-based videoconferencing has been popular in higher education but IPbased videoconferencing and streaming media are increasingly becoming a critical part of instructional technologies. Future studies may want to examine transactional distance issues with a communication studies' approach in blended learning or online learning environments, as undergraduate and graduate degree programs are increasingly adopting these educational systems. Garrison (2000) asserted "theory in distance education must evolve to reflect current and emerging innovative practices of designing and delivering education a distance" (p.14).

The fifth direction for future study suggests paying closer attention to the construct variables of transactional distance and other communication variables that would affect transactional distance. In this study, impersonal solidarity operationally defined transactional distance because it was regarded as the major construct of transactional distance. The interpersonal solidarity scale produced high reliability and yielded significant findings of the study. One may duplicate this study using interpersonal solidarity as transactional distance toward teachers as well as that toward peer students in 
videoconferencing, blended or online learning environments. The results will give an opportunity to compare the level of perceived TDST with TDSS.

\section{Implication for Practice}

The findings of this study challenged the 'no-significance' phenomenon in distance education research. Although students in distance learning and traditional learning may not have any significant difference in their learning, the perceptions of the student learning process should not be the same. In this study, it is found that offsite students compensate for lack of direct interaction with their instructor by building stronger solidarity with peers in their site. Offsite students perceived significantly higher interpersonal solidarity toward their site students compared to onsite students, which are consistent to the findings of Jung's (2003) study.

This study can help educators to gain a better understanding of how collaborative learning projects are affected by a distance learning environment compared to a traditional classroom where a teacher is physically present. As this study indicated, offsite students may have higher solidarity among themselves, and as Jung (2003) found, the absence of teachers strengthens the interpersonal solidarity and affect their learning process, the instructor may misunderstand offsite students. Jung (2003) quoted an offsite students' word, "because the professor is not in the classroom, it creates team effort that we as the $\mathrm{W}$ cohort try to help teammates solve the problem.... That makes us a bond as a group." However, the instructor of the course misunderstood offsite students' collaborative work with lack of attention to the instructor. Jung (2003) quoted an instructor who perceived low offsite students' involvements, "I still think the main difficulties are engaging students in the distant site (offsite students).... It is very difficult 
engaging them, because there is not a person (instructor) there." On the other hand, an offsite student indicated that "you can't hear us when we are always talking. So there is a lot of interaction among the W site students. You just don't hear down here (On-site campus).” Jung (2003) indicated how teachers can misinterpret offsite students's solidarity and involvement in the traditional point of teacher-centered view.

The distance education environment can be challenging for teachers in that there are limited levels of control over students, since the communication between teacher and students are mediated by the instructional technologies. Garrison, (2000) stated that "consideration of these transactional elements will determine the appropriate balance of control which can only be assessed and constantly adjusted through sustained two-way communication" (p. 10).

The study also provides the opportunity to address adult learner characteristics and student motivation issues. Another implication of this study will be designing distance courses with consideration of diverse communication opportunities among the learners and factors that can increase student motivation.

The implications extend beyond the traditional educational environment and could be expanded to include corporate, medical and military environments in which a large portion of their training is done almost solely through remote means, such as video conferencing, interactive video. A way to better target instruction to these groups would be to understand the strong group/team dynamic which gives them cohesiveness in remote environments whether that can be workers on a cannery in the ocean off Finland or a military team isolated behind military lines. This would even extend to the current push towards long-term space travel and the problems involved with continuing 
instruction while in-flight. This is a real problem facing NASA at this time. It is important for teachers to understand that in this changing environment the Atlas theory of instruction, in which the teacher is always the center of control of the learning process, is changing.

In summary, the findings of this study indicated that students in distance learning environments have different social experience compared to the more traditional classroom learning environment. The implication of this study for practices include helping educators to gain understanding of the learner's experience in distance educational format and providing opportunities for instructional designers to design distance education courses that can encourage collaborative learning and enhance student motivation. The results of this study show how understanding how to help distance learners make social connections could be a key to improving persistence in distance learning environments.

Discussions: Transactional Issues and Communication Variables

Distance education has come a long way in terms of using diverse communication systems to effectively deliver courses. In the $20^{\text {th }}$ century, distance education focused on "distance constraints and approaches that bridged geographical constrains by way of organizational strategies such as the mass production and delivery of learning package" (Garrison, 2000, p.2), which was generally referred to as the industrial era in distance education. The $21^{\text {st }}$ century represents the post-industrial era. The focus of studies in distance education have shifted to transactional issues, such as teaching-learning transaction, and the transactional issues are predominating over structural constraints (i.e. geographical distance). 
Distance education as an academic field is still in its early childhood. Distance education research has limitations because of the dominance of descriptive research and the lack of validity and reliability of the instruments (Chen \& Willits, 1999). The quality of measurement is critical in building a quantitative science in any discipline. For example, "the development of communication as a discipline has resulted in an explosion of scale tapping various aspects of interpersonal, mass, organization and instructional communication" (Rubin, Palmgree \& Sypher, 1994, ix). As discussed earlier, communication has developed its discipline based on theories and knowledge borrowed from other disciplinary studies, such as psychology, politics, sociology and education, and the interdisciplinary nature, and the accumulated knowledge in the field of communication Studies might contribute to distance education. Communication is a significant determinant of the quality of students' learning experience in distance education (Kuehn, 1994). In short, there are needs for interdisciplinary research between the fields of distance education and communication studies.

This study is designed under the assumption that communication is the core of educational process. Massingill (2002) argued that:

Communication is the heart of education. While education certainly includes selfdiscovery and personal exploration, the process of education may be largely considered to be the sharing of information among educational participants. In order to share information, participants must communicate. Thus, whatever forms educational Communication takes, educational researchers are apt to spend time evaluating it (pp. 1-2). 
Massingill's (2002) argument justifies the application of instructional communication in the distance education context; because it indicated that the communication process occurs in instructional contexts-across subject matter, grade levels, and types of settings. Considering that one of the critical challenges in the field of distance education has been how to respond to the rapid changes brought about by the development of new communication technologies (Gunawardena \& McIsaac, 2001), integrating an instructional communication approach in studying distance education may respond to the challenge.

The significance of this study is in investigating transactional distance from communication studies perspectives. Transactional distance theory identified dialogue, structure and learner autonomy as the key constituent elements of distance education, and these three determine the degree of transactional distance between people. By including dialogue as a second variable, the transactional distance theory differentiates itself from Otto Peters' structure of the industrial model, and Charles Wedemeyer's perspective of independent study, and it advanced the field toward a post-industrial model (Garrison, 2000).

Moore's (1993) transactional distance theory has proposed the interrelationship among the three construct variables; dialogue, structure and learner autonomy. Gorskey and Caspi (2005)'s article, A Critical Analysis of Transactional Distance Theory, provided insightful reviews on published empirical studies that attempted to validate transactional distance theory. Transactional distance theory is limited in that propositions of transactional distance theory have been neither supported nor validated by the empirical research (Gorsky and Caspi, 2005). This is mainly because Moore (1993) did 
not provide any operational definition for any of the theory's constructs, which led researchers to use different operational definitions from the formal ones and to severely compromise construct validity.

Gorsky and Caspi (2005) asked "what, then is the usefulness of the concept ‘transactional distance?” (p. 9). They (2005) answered this question by looking at transactional distance theory as "a historical milestone" which pointed out that "the essential distance in distance education is transactional, not spatial or temporal" (p.9). The only proposition of the theory, Gorsky and Caspi (2005) concluded, is the reverse relationship between transactional distance and dialogue: as dialogue increases, transactional distance decreases. They suggested operational definition for dialogue and transactional distance; dialogue was defined as the potential of understanding and transactional distance was defined as the potential of misunderstanding. They are both measured along the same bipolar dimension, and therefore "any attempt to support or to validate the theory is meaningless, since a quantity and its inverse are being correlated" (p.9). Gorsky and Caspi (2005) proposed that that transactional distance should be measured as a percentage.

This study support Gorsky and Caspi (2005) argues regarding that the core construct of the transactional distance is dialogue or communication, and transactional distance can be measured with communication variable in the same dimension. However, this study disagrees that the defining operational of transactional distance in terms of percentage of potential misunderstanding. Their proposal is arguable since the concept of transactional distance represents the relative nature of psychological and communication 
distance in opposition to the definite concept of the geographical distance, not the percentage of misunderstanding.

In retrospect, this study made efforts to investigate Moore's theory of transactional distance with the concepts of 'immediacy' and 'solidarity,' which are often used in the field of Communication Studies. By doing so, transactional distance theory can represent students' perceptions of others in a distance learning atmosphere. The operational definition of transactional distance between teacher and students (TDST) is students' perception of teachers' immediacy behavior, and that of transactional distance among students (TDSS) is students' perception of learner. This study did not focus on Moore's three constituent variables and focused on the perceptions of the learners to overcome the limitation of teacher centered study. Dron (2004)' criticized that Moore's discussion on the structure and dialogue being reliant on 'the course-centric trappings of traditional educational forms.' This study looked at the relative nature of transactional distance by comparing onsite and offsite students in perceiving transactional distance. In addition the study also looked at if there are significant associations between these perceptions and student motivation toward their course. This study empirically proved that students who do not have their instructor in their classroom have higher transactional distance toward students in the same site than students whose instructors were present in their classroom. The finding is consistent to the findings of Jung (2003)'s qualitative research in the same program. As discussed earlier, this study has a number of limitations with its exploratory nature, interdisciplinary approach and challenges in the quality control in data control process, but these limitations suggested new avenues for future studies. In addition, the study open up new perspectives in providing operational 
definition of transactional distance and encouraging future attempts of integrating the accomplishments of communication discipline in studying distance education.

Gorsky and Caspi (2005) argue that the fundamental western view of education can be explained with Socrates' dialogue, since dialogue has been historically viewed from philosophical and pedagogical approaches. According to Gorsky and Caspi (2005), Transactional distance theory was accepted philosophically and logically since its core proposition (as the amount of dialogue increases, transactional distance decreases) has high face validity and seems both obvious as well as intuitively correct. Indeed, the philosophical impact of Moore's theory remains.

Unfortunately, however, the movement from abstract, formal philosophical definitions to concrete, operational ones caused ambiguity, at best, and collapse of the theory, at worst (pp.9-10).

Gorsky and Caspi (2005) attributed the lack of empirical research on transactional distance theory to the "philosophical approaches are biased a prior toward an anti empirical approach to the study of dialogue" (p.10) According to them, although transactional distance may be conceptually important, "in practical terms, as a measurable dependent variable in a theory or model, the concept has little usefulness" (p.9). This study challenged Gorsky and Caspi's (2005) argument. By providing a measurable communication variable as operational definition of transactional distance, this study showed the potential of transactional distance as a measurable variable in a theory. In general, the goals of theory include explanation, understanding, prediction and social change. Theories help the researchers to answer "why" and "how" questions about our experience, and "are necessary because they help us to understand, communicate and 
predict the nature of a discipline or a field of practice, its purpose, goals and methods" (West \& Turner, 2000, p. 359). This study may become the starting point for transactional distance theory to be stronger theory. 


\section{REFERENCE}

Anderson, J. F. (1979). Teacher immediacy as a predictor of teaching effectiveness. In D. Nimmo (Ed.), Communication yearbook 3 (pp. 543-559). New Brunswick, NJ: Transaction Books.

Anderson, T. D., \& Garrison, D. R. (1995). Transactional issues in distance education: The impact of design in audioteleconferencing. The American Journal of Distance Education, 9(2), 27-45.

Berge, Z. L., \& Mrozowski, S., (2001). Review of research in distance education, 1990 to 1999. The American Journal of Distance Education, 15 (3), 5-19.

Bischoff, W., Bisconer, S. Kooker, B. \& Woods L. (1996). Transactional distance and interactive television in the distance education of health professionals. The American Journal of Distance Education, 10(3), 4-19.

Boyd, R. \& Apps, J. (1980). Redefining the Discipline of Adult Education. San Francisco: Jossey-Bass.

Brown, R. (1965). Social Psychology, New York: Free Press.

Carrell, L. J. \& Menzel, K. E. (2001). Variations in learning, motivation, and perceived immediacy between live and distance education classrooms. Communication Education, 50 (3), pp. 230-240.

Chen, Y. (2001a). Dimensions of transactional distance in the world wide web learning environment: A factor analysis, British Journal of Educational Technology, 32(4), $459-470$.

Chen, Y. (2001b). Transactional distance in world wide web learning environments. Innovations in Education and Teaching International, 38(4), 327-338. 
Chen, Y., \& Willits, F. (1998). A path analysis of the concepts of Moore's theory of transactional distance in a videoconferencing learning environment, Journal of Distance Education, 13(2). Retrieved May 16, 2004, from http://cade.athabascau.ca/vol13.2/chen.html

Chen, Y., \& Willits, F. (1999). Dimensions of educational transactions in a videoconferencing learning environment. American Journal of Distance Education, 13(1), 45-59.

Christophel, D. M. (1990). The relationships among teacher immediacy behaviors, student motivation, and learning. Communication Education, 39, 323-340.

Cookson, P., \& Chang, Y. (1995). The multidimensional audioconferencing classification system (MACS), American Journal of Distance Education, 9(3), 18-35.

Dron, J. (2004). Termites in the schoolhouse: stigmergy and transactional distance in an E-learning environment, Paper presented at the annual meeting of the ED-Media World Conference on Educational Multimedia, Hypermedia and Telecommunications (1), 263-269.

Dewey, J. \& Bentley, A. F. (1949). Knowing and the known. Boston: Beacon. Retrieved January 1,2005 from http://transactionalview.org/readings/KK.html

Freitas, F. A., Myers, S. A., \& Avtagis, T. A. (1998). Student perception of instructor immediacy in conventional and distributed learning classrooms. 366-372.

Frymier, A. B. (1994). A model of immediacy in the classroom. Communication Quarterly, 42, 133-144. 
Garrison, R. (2000). Theoretical challenges for distance education in the 21 st century: A shift from structural to transactional issues. International Review of Research in Open and Distance Learning, 1(1), 1 - 17.

George, D., \& Mallery, P. (2003). SPSS for Windows step by step: A simple guide and reference. 11.0 update (4th ed.). Boston: Allyn \& Bacon.

Gliem, J. A., \& Gliem, R. R. (2003). Calculating, interpreting and reporting Cronbach's Alpha reliability coefficient for likert-type scales. Midwest Research to practice conference in adult, continuing and community education. 82-88.

Gorham, J. (1988). The relationship between verbal teacher immediacy behavior and student learning. Communication Education, 37, 40-53.

Gorsky, P., \& Caspi, A. (2005). A critical analysis of transactional distance theory. The Quarterly Review of Distance Education, 6 (1), 1-11.

Gunawardena, C. N., \& McIsaac, M. S. (2001). Distance education. In D. H. Jonassen (Ed.), Handbook of research for educational communications and technology: a project of the Association for Educational Communications and Technology (pp. 355-395). Mahwah, N.J.: L. Erlbaum Associates.

Guzley, R. \& Avanzino, S. (April, 2001). Simulated computer-mediated/video-interactive distance learning: A test of motivation, interaction satisfaction, delivery, learning \& perceived effectiveness. Journal of Computer Mediated Communication, 6, [Online]. Retrieved February 16, 2003, from http://www.ascusc.org/jcmc/vol6/issue3/guzley.html 
Hackman, M.Z., \& Walker, K.B. (1990). Instructional Communication in the Televised Classroom: The Effects of System Design and Teacher Immediacy on Student Learning and Satisfaction. Communication Education, 39, 196-206.

Hillman, D. C. A., Willis, D. J., \& Gunawardena, C. N. (1994). Learner-interface interaction in distance education: An extension of contemporary models and strategies for practitioners. The American Journal of Distance Education, 8(2), $30-42$.

Hopper, D. A. (2000). Learner characteristics life circumstances, and transactional distance in a distance education setting. (Doctoral dissertation, Wayne State University, 2003). Dissertation Abstracts International, 61, P. 3962.

Huang, H. (2002). Toward constructivism for adult learners in online learning environments. British Journal of Educational Technology, 33 (1), 22-37.

Jung, H. Y. (2003). “I wasn’t forced”: Videoconferencing and Adult Learners. In D. Lassner (Ed.), Proceedings of ED-MEDIA World Conference on Educational Multimedia, Hypermedia \& Telecommunications, 1574-1577.

Jung, I. (2001). Building a theoretical framework of web-based instruction in the context of distance education. British Journal of Educational Technology, 32(5), 525-535.

Kelsey, K. (2000). Participant interaction in a course delivered by interactive compressed video technology. The American Journal of Distance Education, 14(1), 63-74.

Kilgore, D. W. (1999). Understanding learning in social movements: a theory of collective learning, International Journal of Lifelong Education, 18 (3), 191-202.

Kuehn, S. A. (1994). computer-mediated communication in instructional settings: A research agenda. Communication Education, 43 (2), 171-183. 
Lally, V., \& Barrett, E. (1999). Building a learning community on-line: Towards socioacademic interaction. Research Papers in Education, 14(2), 147-163.

Lieb, S. (1999). Principles of Adult Learning [Online] Available:

http://www.hcc.hawaii.edu/intranet/committees/FacDevCom/guidebk/teachtip/adults2.htm [December, 2002].

Lowell, N. O. (2004). An Investigation of Factors Contributing to Perceived Transactional Distance in an Online Setting. (Doctoral dissertation, dissertation. University of Northern Colorado, 2004). Dissertation Abstracts International,

Mazur, J. M. (2000). Applying insight from film theory and cinematic technique to create a sense of community and participation in a distributed video environment. Journal of Computer-Mediated Communication, 5 (4) [Online], Available: http://www.ascusc.org/jcmc/vol5/issue4/problems

Massingill, K.B. (2002), A comparison of communication motives of on-site and off-site students in videoconference-based courses. (Doctoral dissertation, Wayne State University, August 2002).

McCroskey, J. C. \& Richmond, V. P. (1992).An instructional communication program for in-service teachers. Communication Education, 41(2), 216-223.

McIsaac, M. S. \& Gunawardena, C. W. (1996). Distance Education. In D. H. Jonassen (Ed.), Handbook of Research for Educational Communications and Technology (pp. 403-437). New York: Macmillan.

Millette, D. M., \& Gorham, J. (2002). Teacher Behavior and Student Motivation. In J. L. Chesebro \& J. C. McCroskey (Eds.), Communication for Teachers (pp. 141-153). Boston: Allyn and Bacon. 
Moore, M. G. (1980). Independent study. In Redefining the Discipline of Adult Education, eds. R. D. Boyd and J.W. Apps, (pp. 16-31). San Francisco: JosseyBass.

Moore, M. G. (1989). Editorial: Three type of interaction. The American Journal of Distance education, 3 (2), 1-6.

Moore, M. G. (1990). Recent contributions ot the theory of distance education. Open Learning 5(3):10-15.

Moore, M. G. (1991). Distance education theory. The American Journal of Distance Education, 3 (2), 1-6.

Moore, M.G. (1993). Theory of transactional distance. In D. Keegan (Ed.), Theoretical Principles of Distance Education (pp.22-38). New York: Routledge.

Moore, M. G., \& Kearsley, G. (1996). Distance education: A systems view. Belmont, CA: Wadsworth.

Mottet, T. P., \& Stewart, S. L. (2002). Teacher communication in the distance education context. In J. P. Chesebro \& J. C. McCroskey (Eds.) Communication for Teachers (pp. 157-171). Boston, MA: Allyn \& Bacon.

Mottet, T. P. (1998) Interactive television instructors' perceptions of students' nonverbal responsiveness and effects on distance teaching. Unpublished doctoral dissertation, West Virginia University.

Phipps, R., \& Merisotis, J.(1999). What's the Difference? A Review of Contemporary Research on the Effectiveness of Distance Learning in Higher Education. Washington, DC: Institute for Higher Education Policy. 
Plax, T. G., Kearney, P., McCroskey, J. C., \& Richmond, V. P. (1986). Power in the classroom VI: Verbal control strategies, nonverbal immediacy and affective learning. Communication Education, 35, 43-55.

Ponzurick, T.G., France, K., \& Logar, C.M. (2000). Delivering Graduate Marketing Education: An Analysis of Face-to-Face Versus Distance Education. Journal of Marketing Education, 22(3), 180-187.

Rao, V. S., \& Dietrich, G. B. (1996). The study of interactive-television based classrooms: Some theoretical and methodological issues. International Journal of Instructional Media, 23 (4), 305-328.

Richmond, V. P. (1990). Communication in the classroom: Power and motivation. Communication Education, 39, 181-195.

Richmond, V. P., \& McCroskey, J. C. (Eds.) (1992). Power in the Classroom: Communication, Control, and Concern. Lawrence Erlbaum Associates.

Richmond, V. P., Gorham, J.S., \& McCroskey, J. C. (1987). The relationship between selected immediacy behaviors and cognitive learning. Communication Yearbook, 10, 574-590.

Richmond, V. P. (2002). Teacher nonverbal Immediacy: Use and Outcomes. In Communication Teachers. In J. P. Chesebro \& J. C. McCroskey (Eds.) Communication for Teachers (pp. 65-82). Boston, MA: Allyn \& Bacon. Richmond, V. P., \& McCroskey, J. C.(2000). Nonverbal behavior in interpersonal relationships. Boston, MA:Allyn and Bacon. 
Richmond, V. P., McCroskey, J. C., \& Johnson, A. E. (2003). Development of the Nonverbal immediacy Scale (NIS): Measures of self-and other-perceived nonverbal immediacy, Communication Quarterly, 51, 502-515.

Rubin, R., P. Palmgreen, and H. Sypher (eds.), Communication Research Measures: A Sourcebook, New York: Guilford, 1994.Saba, F. (1988) 'Integrated telecommunications systems and instructional transaction', 2(3), p. 17.

Saba, F., \& Shearer, R.L. (1994 a). Verifying key theoretical concepts in a dynamic model of distance education. The American Journal of Distance Education, 8(1), $36-59$

Saba, F. \& Shearer, R.L. (1994 b) Distance in Education. In David H. Jonassen (Ed.) Handbook of research for educational communications and technology. New York: Macmillan.

Shin, N. (2001). Beyond interaction: transactional presence and distance learning Unpublished doctoral dissertation, Pennsylvania State University.

Souder, W. E. (1993). The effectiveness of traditional vs. satellite delivery in three management of technology master's degree programs. The American Journal of Distance Education, 7(1), 37-53.

Stein, D. S., Wanstreet, C. E., Calvin, J., Overtoom, C. \& Weaton, J. E. (2005). Bridging the transactional distance gap in online learning environments. The American Journal of Distance Education, 19(2), 105-118.

Wedemeyer, C. A. (1971). Independent study. In R. Deighton (Ed.), Encyclopediaof Education IV (pp. 548-557). New York: McMillan. 
West, R., \& Turner, L. H. (2000). Introducing communication theory. Mountain View, CA: Mayfield.

Wheaton, J., Stein, D., Calvin, J., Overtoom, C., \& Wanstreet, C. E. (2003). Building online learning communities: Factors supporting collaborative knowledgebuilding. Proceedings of the 19th Annual Conference on Distance Teaching and Learning. Retrieved March 17th, 2005, from http://www.uwex.edu/disted/conference/Resource_library/proceedings/03_40.pdf

Wheelss, L. R. (1976). Self-disclosure and interpersonal solidarity: Measurement, Validation, and relationships. Human Communication Research, 3, 47-61.

Wheelss, L. R. (1978). A follow-up study of the relationships among trust, disclosure, and interpersonal solidarity. Human Communication Research, 4, 143-157.

Wheeless, Wheeless and Dickson- Markman (1982). A research note: The relations among social and task perceptions in small groups. Small Group Behavior. 13 (3), 373-384.

Zhang, A. (2003). Transactional distance in web-based college learning environments: Toward measurement and theory construction (Doctoral dissertation, Virginia Commonwealth University, 2003). Dissertation Abstracts International, 64, 477. 


\section{APPENDIX A}

\section{Cover Letter to Students}

Dear Participants:

I am doctoral student in Technology Education Program at West Virginia University and I am writing this to ask your participation for my survey. This research is a partial fulfillment of the requirement for my doctoral dissertation. The purpose of this dissertation research is to investigate how students perceive their course, instructor and peer students in videoconferencing courses.

All of the instruments used in this survey are highly reliable and valid indicators of students' perceptions, and they have been used in previous research studies. The estimated time to finish this survey is 15 minutes.

Please think about each statement in relation to the course your current course, the instructor and classmates in your site and those in distant sites. (Please make sure that the instructor and the courses are matched.)

Participation for current study is voluntary, and subjects' responses will be kept anonymous. If you have any questions about this research project, please email hjung@mix.wvu.edu. I really appreciate your participation.

Sincerely,

Hye Yoon Jung 


\section{APPENDIX B}

Survey Instruments

Age

Gender

Marital Status

Male Female

Single _ Married

Divorced/Separated

Widowed

Employment Status

Employed ___ Unemployed

Self-Employed/ Small Business Owner

Years Employed

Specify (Years/ months)

Please indicate which cohort you are in (check the cohort and indicate your site)

口 EM04

Elkins

Morgantown

- CMP05

__Charleston ___ Morgantown __ Parkersburg

- BLM05

__Beckley__ Lewisburg ___ Morgantown

a MMW06

__ Martinsburg__ Morgantown___ Wheeling

a MSW04

Morgantown_Shepherdstown_ Wheeling

EMM07

__ Elkins ___ Moorefield ___ Morgantown

How long have you been in the Program?

First semester Second semester

Fifth semester sixth (or more) semester

Third semester

Fourth semester

Which best describes your racial / ethnic background?

1] Caucasian/White

African American/ Black

Asian

Hispanic or Latino

Others(Specify)

Educational Background (Check one and specify degree earned before this program)

- Associate Degree

- Baccalaureate Degree

- Maters Degree

口 Doctorate Degree

口 Other (Specify) 


\section{Section I: Nonverbal Immediacy Measure}

DIRECTIONS: The following statements describe the ways some people behave while talking with or to others. Indicate in the space at the left of each item the degree to which you believe the statement applies to the teacher in this class. Please use the following 5point scale: $1=$ Never; $2=$ Rarely; $3=$ Occasionally; $4=$ Often; $5=$ Very Often

1. He/she uses his hands and arms to gesture while talking to people.

2. $\mathrm{He} / \mathrm{she}$ touches others on the shoulder or arm while talking to them.

3. He/she uses a monotone or dull voice while talking to people.

4. He/she looks over or away from others while talking to them.

5. He/she moves away from others when they touch him while we are talking.

6. $\mathrm{He} / \mathrm{she}$ has a relaxed body position when he talks to people.

7. $\mathrm{He} / \mathrm{she}$ frowns while talking to people.

8. He/she avoids eye contact while talking to people.

9. $\mathrm{He} / \mathrm{she}$ has a tense body position while talking to people.

10. $\mathrm{He} / \mathrm{she}$ sits close or stands close to people while talking with them.

11. His/her voice is monotonous or dull when he talks to people.

12. He/she uses a variety of vocal expressions when he talks to people.

13. He/she gestures when he talks to people.

14. $\mathrm{He} / \mathrm{she}$ is animated when he talks to people.

15. He/she has a bland facial expression when he talks to people.

16. He/she moves closer to people when he talks to them.

17. $\mathrm{He} / \mathrm{she}$ looks directly at people while talking to them.

18. He/she is stiff when he talks to people.

19. He/she has a lot of vocal variety when he talks to people.

20. He/she avoids gesturing while he is talking to people.

21. He/she leans toward people when he talks to them.

22. He/she maintains eye contact with people when he talks to them.

23. He/she tries not to sit or stand close to people when he talks with them.

24. He/she leans away from people when he talks to them.

25. He/she smiles when he talks to people.

26. He/she avoids touching people when he talks to them. 


\section{Section II: Interpersonal Solidarity Measure}

DIRECTIONS: Please mark these scales to indicate how you related to PEER STUDENTS AT YOUR SITE and AT DISTANT SITES (IN THE OTHER SITES). Please mark the following statements to indicate whether you (1) strongly disagree, (2) disagree, (3) moderately disagree (4) are undecided, (5) moderately agree (6) agree, or (7) strongly agree with each statement.

1. We were very close to one another

2. These people had a great deal of influence over my behavior.

3. I trusted these people completely.

4. We felt very differently about things.

5. I willingly disclosed a great deal of positive and negative things about myself, honestly, and fully (in depth) to these people.

6. We did not really understand each other

7. They willingly disclosed a great deal of positive and negative things about themselves, honestly, and fully (in depth) to these people.

8. I distrusted them

9. I liked them much more than most people I knew at that time.

10. I seldom interacted/communicated with them.

11. I loved them.

12. I understood them and who they really were.

13. I disliked them.

14. I interacted/communicated with them much more than with most people I know.

15 . We were not very close at all.

16. We shared a lot in common.

17. We did a lot of helpful things for each other.

18. I had little in common with them.

19. I felt very close to them.

20. We shared some private ways of communicating with each other.
Students in your site SD D MD U MA A SA

Students in the other sites

$\begin{array}{lllllll}1 & 2 & 3 & 4 & 5 & 6 & 7\end{array}$

$\begin{array}{lllllll}1 & 2 & 3 & 4 & 5 & 6 & 7\end{array}$

SD D MD U MA A SA

$\begin{array}{lllllll}1 & 2 & 3 & 4 & 5 & 6 & 7\end{array}$

$\begin{array}{lllllll}1 & 2 & 3 & 4 & 5 & 6 & 7\end{array}$

$\begin{array}{lllllll}1 & 2 & 3 & 4 & 5 & 6 & 7\end{array}$

$\begin{array}{lllllll}1 & 2 & 3 & 4 & 5 & 6 & 7\end{array}$

$\begin{array}{lllllll}1 & 2 & 3 & 4 & 5 & 6 & 7\end{array}$

$\begin{array}{lllllll}1 & 2 & 3 & 4 & 5 & 6 & 7\end{array}$

$\begin{array}{lllllll}1 & 2 & 3 & 4 & 5 & 6 & 7\end{array}$

$\begin{array}{lllllll}1 & 2 & 3 & 4 & 5 & 6 & 7\end{array}$

$\begin{array}{lllllll}1 & 2 & 3 & 4 & 5 & 6 & 7\end{array}$

$\begin{array}{llllllllllllll}1 & 2 & 3 & 4 & 5 & 6 & 7 & 1 & 2 & 3 & 4 & 5 & 6 & 7\end{array}$

$\begin{array}{llllllllllllll}1 & 2 & 3 & 4 & 5 & 6 & 7 & 1 & 2 & 3 & 4 & 5 & 6 & 7\end{array}$

$\begin{array}{llllllllllllll}1 & 2 & 3 & 4 & 5 & 6 & 7 & 1 & 2 & 3 & 4 & 5 & 6 & 7\end{array}$

$\begin{array}{llllllllllllll}1 & 2 & 3 & 4 & 5 & 6 & 7 & 1 & 2 & 3 & 4 & 5 & 6 & 7\end{array}$

$\begin{array}{llllllllllllll}1 & 2 & 3 & 4 & 5 & 6 & 7 & 1 & 2 & 3 & 4 & 5 & 6 & 7\end{array}$

$\begin{array}{llllllllllllll}1 & 2 & 3 & 4 & 5 & 6 & 7 & 1 & 2 & 3 & 4 & 5 & 6 & 7\end{array}$

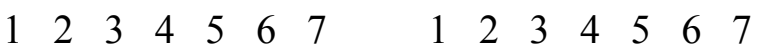

$\begin{array}{llllllllllllll}1 & 2 & 3 & 4 & 5 & 6 & 7 & 1 & 2 & 3 & 4 & 5 & 6 & 7\end{array}$

$\begin{array}{llllllllllllll}1 & 2 & 3 & 4 & 5 & 6 & 7 & 1 & 2 & 3 & 4 & 5 & 6 & 7\end{array}$

$\begin{array}{llllllllllllll}1 & 2 & 3 & 4 & 5 & 6 & 7 & 1 & 2 & 3 & 4 & 5 & 6 & 7\end{array}$

$\begin{array}{llllllllllllll}1 & 2 & 3 & 4 & 5 & 6 & 7 & 1 & 2 & 3 & 4 & 5 & 6 & 7\end{array}$

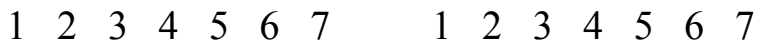

$\begin{array}{llllllllllllll}1 & 2 & 3 & 4 & 5 & 6 & 7 & 1 & 2 & 3 & 4 & 5 & 6 & 7\end{array}$

$\begin{array}{llllllllllllll}1 & 2 & 3 & 4 & 5 & 6 & 7 & 1 & 2 & 3 & 4 & 5 & 6 & 7\end{array}$ 
Section III: Student Motivation Scale

DIRECTIONS: Please circle the number toward either word which best presents your feelings about your course.

$\begin{array}{lllllllll}\text { Motivated } & 1 & 2 & 3 & 4 & 5 & 6 & 7 & \text { Unmotivated } \\ \text { Excited } & 1 & 2 & 3 & 4 & 5 & 6 & 7 & \text { Bored } \\ \text { Uninterested } & 1 & 2 & 3 & 4 & 5 & 6 & 7 & \text { Interested } \\ \text { Involved } & 1 & 2 & 3 & 4 & 5 & 6 & 7 & \text { Uninvolved } \\ \text { Dreading it } & 1 & 2 & 3 & 4 & 5 & 6 & 7 & \text { Looking forward to it. }\end{array}$




\section{APPENDIX C \\ Nonverbal Immediacy Scale-Observer Report (NIS-O)}

This is the most up-to-date measure of nonverbal immediacy as an other- or observerreport. Earlier measures have had problematic alpha reliability estimates. This instrument may be used for any target person (most earlier measures were designed only for observations of teachers). Alpha reliability estimates around .90 should be expected. This measure also has more face validity than previous instruments because it has more and more diverse items. Its predictive validity is also excellent.

When using this instrument it is important to recognize that the difference in these observer-reports between females and males is not statistically different. Hence, it is unnecessary to employ biological sex of the person completing the instrument in data analyses involving this instrument. It is recommended that the COMBINED norms be employed in interpreting the results employing this instrument. However, sex differences of the target persons on whom the instrument is completed may be meaningful. This possibility has not been explored in the research to date (September, 2003).

DIRECTIONS: The following statements describe the ways some people behave while talking with or to others. Please indicate in the space at the left of each item the degree to which you believe the statement applies to (fill in the target person's name or description). Please use the following 5-point scale:

$1=$ Never; 2 = Rarely; $3=$ Occasionally; $4=$ Often; $5=$ Very Often

1. He/she uses her/his hands and arms to gesture while talking to people.

2. He/she touches others on the shoulder or arm while talking to them.

3. He/she uses a monotone or dull voice while talking to people.

4. He/she looks over or away from others while talking to them.

5. He/she moves away from others when they touch her/him while they are talking.

6. He/she has a relaxed body position when he/she talks to people.

7. He/she frowns while talking to people.

8. He/she avoids eye contact while talking to people.

9. He/she has a tense body position while talking to people. 
10. He/she sits close or stands close to people while talking with them.

11. Her/his voice is monotonous or dull when he/she talks to people.

12. He/she uses a variety of vocal expressions when he/she talks to people.

13. He/she gestures when he/she talks to people.

14. $\mathrm{He} / \mathrm{she}$ is animated when he/she talk to people.

15. He/she has a bland facial expression when he/she talks to people.

16. He/she moves closer to people when he/she talks to them.

17. He/she looks directly at people while talking to them.

18. He/she is stiff when he/she talks to people.

19. He/she has a lot of vocal variety when he/she talks to people.

20. He/she avoids gesturing while he/she is talking to people.

21. He/she leans toward people when he/she talks to them.

22. He/she maintains eye contact with people when he/she talks to them.

23. He/she tries not to sit or stand close to people when he/she talks with them.

24. He/she leans away from people when he/she talks to them.

25. He/she smiles when he/she talks to people.

26. He/she avoids touching people when he/she talks to them.

\section{Source:}

Richmond, V. P., McCroskey, J. C., \& Johnson, A. E. (2003). Development of the Nonverbal Immediacy Scale (NIS): Measures of self- and other-perceived nonverbal immediacy. Communication Quarterly, 51, 502-515 


\section{APPENDIX D}

\section{Student Motivation Scale}

Instructions: Please circle the number toward either word which best presents your feelings about your

1. Motivated

2. Excited

3. Uninterested

4. Involved

5. Dreading it

$\begin{array}{lllllll}1 & 2 & 3 & 4 & 5 & 6 & 7 \\ 1 & 2 & 3 & 4 & 5 & 6 & 7 \\ 1 & 2 & 3 & 4 & 5 & 6 & 7 \\ 1 & 2 & 3 & 4 & 5 & 6 & 7 \\ 1 & 2 & 3 & 4 & 5 & 6 & 7\end{array}$

Unmotivated

Bored

Interested

Uninvolved

Looking forward to it.

Items 3, 5 were reverse coded before summing. 


\section{APPENDIX E \\ Interpersonal Solidarity Scale}

Please mark these scales to indicate how you related to Please mark the following statements to indicate whether you (1) strongly disagree, (2) disagree, (3) moderately disagree (4) are undecided, (5) moderately agree (6) agree, or (7) strongly agree with each statement.

1. We are very close to each other.

2. This person has a great deal of influence over my behavior.

3. I trust this person completely.

4. We feel very differently about things.

5. I willingly disclose a great deal of positive and negative things about myself, honestly, and fully (in depth) to this person.

6. We do not really understand each other.

7. This person willingly disclose a great deal of positive and negative things about themselves, honestly, and fully (in depth) to me.

8. I distrusted this person.

9. I like this person much more than most people I know.

10. I seldom interact/communicate with this person.

11. I love this person.

12. I understand them and who s/he really is.

13. I dislike this person.

14. I interact/communicate with this person much more than with most people I know

15. We are not very close at all.

16. We share a lot in common.

17. We do a lot of helpful things for each other.

18. I have little in common with this person

19. I feel very close to this person.

20. We share some private way(s) of communicating with each other.

Note. Items $4,6,8,10,13,15$, and 18 are reverse-coded before items are summed. 


\section{APPENDIX F}

\section{W. WestVirginiaUniversity \\ College of Business and Economics}

December 3,2004

Hye Yoon Jung

Technology Education

Dear Ms. Jung:

In response to your request to contact students in the Executive MBA program for participation in your study, we are please to assist you in this process. We will contact our students and request their participation on your behalf. We will forward your request to our students. Students will respond via VISTA.

Sincerely,

Paul J. streaket

Director of the MBA Programs 


\section{Hye Yoon Jung}

Phone (850)-645-7299

Email: hyjung@1si.fsu.edu

151 Bliss Dr. Apt. 11

Tallahassee FL 32310

\section{EDUCATION}

Ed. D.

WEST VIRGINIA UNIVERSITY

- May 2006

Technology Education, Department of Advanced Education

Dissertation: Students' Perception of Psychological Distance and

Students' Motivation toward their course in Distance Education

M. A.

WEST VIRGINIA UNIVERSITY

- Aug. 2001

Master of Art in Communication Studies

Areas of Specialization: Intercultural and Instructional

Communication, and Communibiology (biological aspects of

communication

M. S.

- Dec. 1999

WEST VIRGINIA UNIVERSITY

Master of Science in Journalism

Areas of Specialization: Mass Communication and Advertising.

Thesis: Collegiate Sports Sponsorship and Brand Awareness:

A Study of Collegiate Sponsorship at a Football Game

B. S.

- Feb. 1997

YEOUNGNAM UNIVERSITY, Daegu, South Korea

Bachelor of Science in Political Science \& Diplomacy

\section{RESEARCH EXPERIENCE}

\section{Peer-Reviewed Journal}

Jung, H. Y., \& McCroskey, J. C. (2004). Communication apprehension in a first language and self-perceived competence as predictors of communication apprehension in a second language: a study of speakers of English as a second language, Communication Quarterly 52 (2), 170-183.

\section{Technical Report}

Webb-Dempsey, J., Heinen, E., Hurst, J., Jung, H. Y., McClellan, C. M., \& Moore, L. (2005). Project School Action for Emergencies (SAFE): Final Evaluation Report. (Submitted to Harrison County Public Schools). 


\section{Conference Proceedings}

Jung, H. Y., (2005). Immediacy, Solidarity and Learner's Motivation In Videoconferencing Learning Environment. Proceedings of Society for Information Technology \& Teacher Education (SITE) 2005 International Conference, Association for the Advancement of Computing in Education, 445-447.

Jung, H. Y. (2004). Educational transaction through the lens of communication studies: videoconferencing learning environments. Proceedings of EDMedia World Conference World Conference on Educational Multimedia, Hypermedia \& Telecommunications, Association for the Advancement of Computing in Education (1), 1383-1386

Jung, H. Y., \& MacLennan, B. (2004). Two problems and one solution: collaboration in preparing tomorrow's leaders in education. Proceedings of Society for Information Technology \& Teacher Education (SITE) 2004 International Conference, Association for the Advancement of Computing in Education, 2309-2311.

Jung, H. Y. (2003). What lies beneath panacea? - the use of instructional technology in the classroom. Proceedings of E-Learn World Conference on E-Learning in Corporate, Government, Healthcare, \& Higher Education, Association for the Advancement of Computing in Education, 557-560.

Jung, H. Y. (2003). "I wasn't forced": videoconferencing and adult learners. In D. Lassner (Ed.), Proceedings of ED-MEDIA World Conference on Educational Multimedia, Hypermedia \& Telecommunications, 1574-1577.

Jung, H. Y. (1999). Collegiate sports sponsorship and brand awareness: a study of collegiate sponsorship at a football game. Unpublished Master's Thesis. Morgantown, WV: West Virginia University.

\section{Professional Conference Presentations}

Jung, H. Y. (2005). Comparison of Motivation, Perceived Immediacy, Group Solidarity between Onsite Classes and Distant Classes. Paper was accepted by the ED- Media World Conference World Conference on Educational Multimedia, Hypermedia \& Telecommunications for June 27July 2, 2005 in Montreal, Canada.

Jung, H. Y. (2005). Immediacy, Solidarity and Learner Empowerment in Distance Education, Paper was presented in the Society for Information Technology $\&$ Teacher Education (SITE) International Conference for March 1-5, 2005 in Phoenix. AZ

Jung, H. Y. (2005). Secure Online Environment (SOLE); In-House Online Solution for Educational Needs. Paper was accepted by the Eastern Educational Research Association (EERA) Conference for March 2-5, 2004 in Sarasota, Florida, USA.

Jung, H. Y. (2005). Psychological Distance in Distance Education: Immediacy, Solidarity and Learner Empowerment. Paper was accepted by the Eastern Educational Research Association (EERA) Conference for March 2-5, 2004 in Sarasota, Florida, USA. 
Jung, H. Y. \& McCroskey, J. C. (2004). Communication Apprehension in a First Language and Self-Perceived Competence as Predictors of Communication Apprehension in a Second Language: A Study of Speakers of English as a Second Language. Paper was presented at the National Communication Association (NCA)'s annual conference for November 11-14, 2004 in Chicago, IL.

Jung, H. Y. (2004). An Empirical Measurement of Transactional Distance, Interpersonal Difference and Community Engagement: Implications for Online Learning. Competitive Paper was presented at the Association for Educational Communications and Technology (AECT)'s annual international convention, for October 20-24, 2004 in Chicago, IL.

Jung, H. Y. (2004). Educational Transaction through the Lens of Communication Studies: Videoconferencing Learning Environments. Paper was accepted by the ED- Media World Conference World Conference on Educational Multimedia, Hypermedia \& Telecommunications for June 21-26, 2004 in Lugano, Switzerland.

Jung, H. Y. (2004). Research-based Web Design \& Usability Guidelines of the National Cancer Institute's Communication Technologies Branch in the U. S. Department of Health and Human Services' (HHS)

Accomplishments. Paper was presented at the annual meeting of the Computing and Technology Symposium for March 30, 2004 in Morgantown, WV.

Jung, H. Y. (2004). Effective Instructional Technology Use in a Large Classroom Setting. Paper was presented at the annual meeting of the Computing and Technology Symposium for March 30, 2004 in Morgantown, WV.

Jung, H. Y. (2004). Two Problems and One Solution: Collaboration in Preparing Tomorrow's Leaders in Education. Paper was presented at the Society for Information Technology \& Teacher Education (SITE) International Conference for March 1-6, 2004 in Atlanta, Georgia, USA.

Jung, H. Y. (2003). What Lies Beneath Panacea? - The Use of Instructional Technology in Classroom. Paper was presented at the annual meeting of the E-Learn World Conference on E-Learning in Corporate, Government, Healthcare, \& Higher Education for November 1-5, 2003 in Phoenix. Arizona, USA.

Jung, H. Y. (2003). "I wasn't forced": Videoconferencing and Adult Learners. Paper was presented at the annual meeting of the ED- Media World Conference on Educational Multimedia, Hypermedia \& Telecommunications for June 23-28, 2003 in Honolulu, Hawaii, USA.

Jung, H. Y. (2002). DNA Decides Destiny: Communication Apprehension of Second Language Speakers in United States. Paper was presented at the annual meeting of the International Communication Association (ICA) Annual Conference for Summer 2002 in Seoul, Korea.

Testing Uncertainty Reduction Theory. Paper was presented in a panel section at the Annual Meeting of the Eastern Communication Association for 2001 in Portland, Maine. 


\section{TEACHING EXPERIENCE}

Fall/2004, Co-instructor for Graduate Course, TE 610: Distance Education, Department of Advanced Education, West Virginia University (WVU), Morgantown, WV

Fall/2003- Spring/2004, Instructor for CIS Intranet Workshops and Tutoring

Mid-Atlantic Cancer Information Service (CIS), Morgantown, WV

Spring/2003, Secure OnLine Environment (SOLE) Workshops

Academic Technologies, Morgantown, WV

Spring/ 2002, Co-instructor for Graduate Course

TE 711: Contemporary Problems in Communication

Department of Advanced Education, West Virginia University

\section{PROFESSIONAL EXPERIENCE}

March 2006 - Present

Instructional Designer, Center for National Security Training and Research

(CNSTAR), Learning System's Institute, Florida State University

June 2004-September 2005

Program Evaluator, School Action for Emergencies, (S .A. F. E), Harrison

County, West Virginia: Technology Opportunities Program (TOP)'s Grant funded by the U.S. Department of Commerce

- Principal Investigator: Dr. Jaci Webb-Dempsey and Dr. Ethan Heinen

- Worked as a member of a external evaluation team for Project SAFE, Technology Opportunities Program (TOP)'s Grant

- The nation's first school safety program that will allow emergency response personnel to have access to live video footage via wireless laptop and handheld computers.

August 2003- August 2004

Web Master, Mid-Atlantic Cancer Information Service (CIS) of National Cancer Institute

- Developed Mid-Atlantic Cancer Information Service website

- Developed an intranet to organize departmental documents, facilitated access for off-site staff for training materials and enhanced off-site staff's ability to collaborate in a Secure OnLine Environment (SOLE).

January 2003-June 2004

Instructional Technologist, Academic Technologies, Health Science Center

(HSC), West Virginia University

- Taught HSC faculty and Staff workshops

- Consulted medical faculty with Web based instruction, produced CD-ROM based instruction materials 
June 2002-December 2002

Undergraduate Academic Advisor, Undergraduate Academic Services Center,

West Virginia University

- Responsible for academic advisement for $100+$ undergraduate students

- Guided students in deciding majors

August 2001-May 2002

Event Coordinator, Multicultural and Diversity Initiatives College of Human

Resources and Education (HR \& E), West Virginia University

- Facilitated interaction between faculty, staff, and students

- Promoted a multicultural atmosphere and nurtured diversity initiatives

- Created events, worked with Diversity Task Forces

- Coordinated guest speakers, and worked with people with diverse backgrounds

August 2000-December 2000

Graduate Teaching Assistant (GTA), Communication Studies, West Virginia University

- Assisted Intercultural Communication and Organizational Communication Classes

- Assisted four sections of large-sized undergraduate classes (150-230 students in a class)

- Supervised nine undergraduate teaching assistants

August 1998-July 2000

Foreman in the Production Team, The Daily Athenaeum, Campus newspaper (The DA is one of the top five college newspapers with its advertising sales records.)

- Responsible for special promotion issues

- Participated in overall advertising production process (layout design, photo editing, and setting advertising), supervised the production team, proofreading

\section{PROFESSIONAL ASSOCIATIONS}

- Association for the Advancement of Computing in Education (AACE)

- Association for Educational Communications \& Technology (AECT)

- American Educational Research Association (AERA)

- Eastern Educational Research Association (EERA)

- International Communication Association (ICA) 


\section{SERVICE}

Service at International Conventions/ Conferences

- Member of 'Standards and Accreditation Committee' s sub-committee at Association for Educational Communications and Technology (AECT)'s annual international convention, for October 18-22, 2005 in Orlando, FL.

- Facilitator at Association for Educational Communications and Technology (AECT)'s annual international convention, for October 18-22, 2005 in Orlando, FL.

- Volunteer at Association for Educational Communications and Technology (AECT)'s annual international convention, for October 18-22, 2005 in Orlando, FL.

- Volunteer at Society for Information Technology \& Teacher Education (SITE) International Conference for March 1-5, 2005 in Phoenix. AZ

- Facilitator at the Association for Educational Communications and Technology (AECT)'s annual international convention, for October 20-24, 2004 in Chicago, IL.

- Conference Paper Reviewer, Association for Educational Communications and Technology (AECT)'s annual international convention, for October 2024, 2004 in Chicago, IL.

- Presider at Society for Information Technology \& Teacher Education (SITE) 2004 International Conference

- Volunteer at Society for Information Technology \& Teacher Education (SITE) 2004 International Conference

\section{Community Service in Morgantown, West Virginia}

Korean Community Event Coordinator, International Festival (2001)

- Created an event to share message of "World Peace" for the International festival at the West Virginia University

- Increased cultural awareness, which was covered by the regional newspaper The Dominion Post

Event Coordinator at the College of Human Resource and Education, Appreciation Day (2001)

- Created 'Appreciation Day' for students and faculty members who have contributed in nurturing the multicultural and diversity initiatives in the College of Human Resources and Education 
Guest Speaker at West Preston Middle School (2000)

- Presented Korean culture to help a student who was adopted from Korea and to increase cultural awareness

Guest Speaker for Intercultural Communication course (1999)

- Presented in a graduate Intercultural Communication course in 1999 through the Department of Communication Studies at West Virginia University

\section{SERVICE-RELATED HONORS}

- Appreciation Certificate from the College of Human Resources and Education in recognition of dedicated support of the Multicultural and Diversity Initiatives

- Appreciation Certificate from the Intensive English Program (IEP) in recognition of friendship and support of the West Virginia University IEP Executive and Professional Program

- The Daily Athenaeum Senior Service Award in recognition of performance in the duties and attainment of a level of excellence, which has contributed overall inspiration to associates on the staff and stability to the entire publication 